\title{
Achievements and Trends in Photoelectrocatalysis: from Environmental to Energy Applications
}

\author{
Guilherme Garcia Bessegato $^{1}$. Thaís Tasso Guaraldo ${ }^{1}$ - Juliana Ferreira de Brito ${ }^{1}$. \\ Michelle Fernanda Brugnera $^{2}$ - Maria Valnice Boldrin Zanoni ${ }^{1}$
}

Published online: 4 June 2015

(C) Springer Science+Business Media New York 2015

\begin{abstract}
The great versatility of semiconductor materials and the possibility of generation of electrons, holes, hydroxyl radicals, and/or superoxide radicals have increased the applicability of photoelectrocatalysis dramatically in the contemporary world. Photoelectrocatalysis takes advantage of the heterogeneous photocatalytic process by applying a biased potential on a photoelectrode in which the catalyst is supported. This configuration allows more effectiveness of the separation of photogenerated charges due to light irradiation with energy being higher compared to that of the band gap energy of the semiconductor, which thereby leads to an increase in the lifetime of the electron-hole pairs. This work presents a compiled and critical review of photoelectrocatalysis, trends and future prospects of the technique applied in environmental protection studies, hydrogen generation, and water disinfection. Special attention will be focused on the applications of $\mathrm{TiO}_{2}$ and the production of nanometric morphologies with a great improvement in the photocatalyst properties useful for the degradation of organic pollutants, the reduction of inorganic contaminants, the conversion of $\mathrm{CO}_{2}$, microorganism inactivation, and water splitting for hydrogen generation.
\end{abstract}

Maria Valnice Boldrin Zanoni
boldrinv@iq.unesp.br

1 Departamento de Química Analítica, Instituto de Química, Universidade Estadual Paulista "Júlio de Mesquita Filho"-UNESP, Av. Prof. Francisco Degni, 55, 14801-970 Araraquara, SP, Brazil

2 Departamento de Química, Universidade Federal de Mato Grosso UFMT, Av. Fernando Corrêa da Costa, 2367, 78060-900 Cuiabá, MT, Brazil
Keywords Photoelectrocatalytic degradation of organics · Water splitting · photoelectrocatalytic $\mathrm{CO}_{2}$ reduction . $\mathrm{TiO}_{2}$ applied in disinfection $\cdot \mathrm{TiO}_{2}$ nanotubes . Photoelectrosynthesis

\begin{tabular}{ll}
\multicolumn{2}{l}{ Abbreviations } \\
$\mathrm{SC}$ & Semiconductor \\
$E_{\mathrm{bg}}$ & Band gap energy \\
$E_{\mathrm{VB}}$ & Valence band energy \\
$E_{\mathrm{CB}}$ & Conduction band energy \\
$E_{\mathrm{f}}$ & Fermi level \\
$\mathrm{e}^{-} / \mathrm{h}^{+}$ & Electron/hole pair \\
$\mathrm{h}^{+}$ & Hole \\
$\mathrm{e}^{-}$ & Electron \\
$\mathrm{VB}$ & Valence band \\
$\mathrm{CB}$ & Conduction band \\
$\mathrm{SCL}$ & Space charge layer or depletion layer \\
$E_{\mathrm{fb}}$ & Flat band potential \\
$\mathrm{AOPs}$ & Advanced oxidation processes \\
$\mathrm{TiO}{ }_{2} \mathrm{NTs}$ & TiO ${ }_{2}$ nanotubes array \\
$\mathrm{PEC}$ & Photoelectrocatalytic \\
$\mathrm{TOC}$ & Total organic carbon \\
$\mathrm{CFU}$ & Colony-forming unit \\
$\mathrm{ROS}$ & Reactive oxygen species \\
$\mathrm{THMs}$ & Trihalomethanes \\
$\mathrm{TiO} / \mathrm{ACF}$ & Carbon felt-supported titanium dioxide \\
$\mathrm{TOC}$ & Total organic carbon \\
$\mathrm{VBNC}$ & Viable but not culturable \\
$\mathrm{UV}$ & Ultraviolet \\
$\mathrm{SS}$ & Stainless steel \\
$\mathrm{Gr}$ & Graphite \\
$\mathrm{VC}$ & Vitreous carbon \\
$\mathrm{BDD}$ & Boron-doped diamond \\
$\mathrm{FTO}$ & Fluorine-doped tin oxide \\
&
\end{tabular}




\section{Introduction}

Photoelectrocatalysis is a powerful method derived from the combination of heterogeneous photocatalysis and electrochemical techniques. The method is based on the use of a semiconductor irradiated by light energy equal or greater than its band gap energy simultaneously biased by a gradient potential. It is described as a multidisciplinary field involving surface science, electrochemistry, solid-state physics, and optic knowledge.

The use of semiconductors as photocatalyst, particularly $\mathrm{TiO}_{2}$, is quite known since the $1950[1,2]$. Nevertheless, the great success reported by Fujishima and Honda in 1972 demonstrating that photoelectrocatalytic water splitting is possible when an n-type $\mathrm{TiO}_{2}$ and Pt electrodes are used as anode and cathode, respectively, opened an essentially important window in the area [3]. During that period, the world was passing through an oil crisis and water splitting then emerged as an alternative energy source, attracting the attention of several research areas [2].

Nowadays, photoelectrocatalysis is a technique with consolidated principles that has gained prominence and has been successfully applied in organic compound oxidation [4-6], inorganic ion reduction $[7,8]$, microorganism inactivation $[9,10], \mathrm{CO}_{2}$ reduction $[11,12]$, and production of electricity and hydrogen [13-16]. The subject has since been explored by several researchers and reviews of deserving notoriety $[13$, 17-20]. The most part of these reviews is focused on photocatalytic materials with selected applications. The recent progress of photoelectrocatalysis is intimately related to the advances in materials science, especially in nanomaterials. Highly ordered nanomaterials such as nanotubes, nanowires, nanofibers, nanorods, and nanowalls, among others [18] have become the focus of intensive research owing to a large extent to their high surface area and excellent electronic transport and, thus, worthy of a timely review. Other challenges are the development of stable semiconductor materials able to be activated by solar irradiation. In addition, the development of nanostructured semiconductors and their application in organic compound oxidation, anion reduction, $\mathrm{CO}_{2}$ reduction and electrosynthesis, disinfection, and generation of hydrogen through the photoelectrocatalytic process should be relevant to understand all the potentiality of the technique in a simple revision.

Thus, the aim of this work is to present a compiled and critical review involving fundamental aspects of photoelectrocatalysis, trends and future prospects of the technique applied in environmental protection studies, hydrogen generation, and water disinfection. Special attention will be given to applications with $\mathrm{TiO}_{2}$ and their derivatives, in view of the enormous use in different applications and as a result of their nontoxic, optical, low-cost, and biocompatibility properties.

\section{Fundamentals of Photoelectrocatalysis}

In a semiconductor (SC), orbitals of the atoms are so close that their overlap generates almost continuous regions of energy, forming the so-called electron energy band [21]. As a result, a semiconductor material is characterized by two energy bands separated by an energy, which is termed band gap energy, $E_{\mathrm{bg}}$. A semiconductor at $0 \mathrm{~K}$ is an insulating material because the valence band ( $E_{\mathrm{VB}}$, lower energy level) is fully occupied whereas the conduction band $\left(E_{\mathrm{CB}}\right.$, higher energy level) is totally empty (Fig. 1). The Fermi level, $E_{\mathrm{f}}$, corresponds to the energy of the highest filled state at $0 \mathrm{~K}$, and it lies within the band gap. Hence, to become conductive, charge carriers need to be created, usually by photoexcitation. When a semiconductor surface is irradiated by light $\left(\mathrm{h} v \geq E_{\mathrm{bg}}\right)$, it leads to the generation of electron/hole pair $\left(\mathrm{e}^{-} / \mathrm{h}^{+}\right)$by the promotion of an electron from the valence band (VB) to the conduction band (CB) (Fig. 1), as shown in Eq. 1, where the semiconductor is represented by $\mathrm{MO}_{X}[21,22]$.

$\mathrm{MO}_{X} \stackrel{h v}{\rightarrow} \mathrm{MO}_{X}-\mathrm{e}_{\mathrm{CB}}^{-}+\mathrm{MO}_{X}-\mathrm{h}_{\mathrm{VB}}^{+}$

However, the exploitation of these species in chemical reactions is compromised due to the low photonic efficiency owing largely to the recombination of the $\mathrm{e}^{-} / \mathrm{h}^{+}$pair, as depicted in Eq. 2 [20, 23]:

$\mathrm{MO}_{X}-\mathrm{e}_{\mathrm{CB}}^{-}+\mathrm{MO}_{X}-\mathrm{h}_{\mathrm{VB}}^{+} \rightarrow \mathrm{MO}_{X}+$ heat

Efforts have been made in order to minimize electron/hole recombination [20,24, 25], and the coupling of electrochemical and photocatalysis processes (photoelectrocatalysis) offers this opportunity.

Photoelectrocatalysis is based on the separation of photogenerated $\mathrm{e}^{-} / \mathrm{h}^{+}$pairs by gradient potential [20, 24-28]. The semiconductor is attached on the surface of a conductive substrate and used as photoelectrode. Aiming holistically at a better understanding of the photoelectrocatalysis mechanism, it is necessary to comprehend some phenomena that occur in the semiconductor/electrolyte interface.

When a SC is in contact with a redox electrolyte, there is the formation of a junction (Schottky junction) which causes the change in the electrochemical potential (Fermi level) of the $\mathrm{SC}$ in order to reach an equilibrium at the interface. Thus, a band bending is created within the semiconductor phase, and the amount of this bending is dependent on the difference of the Fermi level of the SC and the electrolyte. Figure 1a-c illustrates the possible band bending at the SC/electrolyte interface. Within the semiconductor, there is a region where the bending takes place, known as the space charge layer (SCL) or depletion layer, which is characterized by the depletion of the majority of the carriers (electrons in an n-type semiconductor and holes in a p-type semiconductor) [18, 21, 25, 29]. 


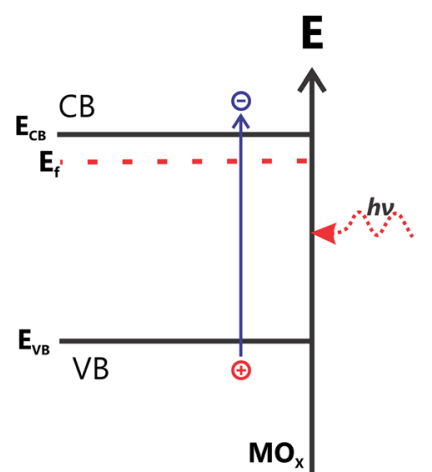

(b)

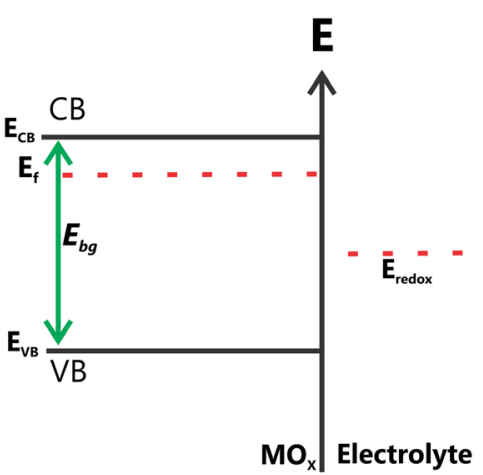

(a)

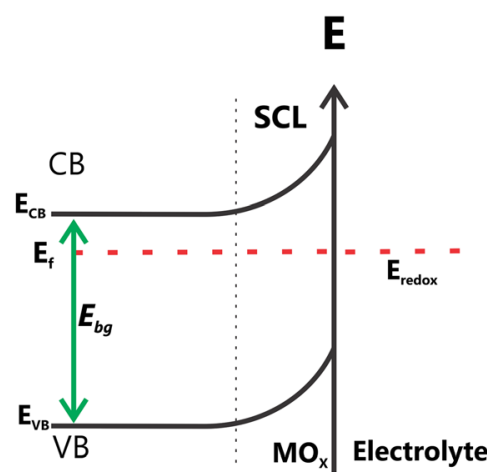

(c)

Fig. 1 a-c Schematic representation of the energy band diagram in a semiconductor and the mechanism of charge carrier generation by photoexcitation

The application of a bias potential is also a way to control the Fermi level of a SC and, therefore, helps to improve the charge separation on the SCL facilitating the reactions of charge carriers on the SC surface. Considering an n-type semiconductor, such as $\mathrm{TiO}_{2}$, if the applied potential is greater than the flat band potential, $E_{\mathrm{fb}}$, of SC (i.e., the potential at which there is no SCL and the bands are flat), there will be an increase of band bending; thus, electrons are depleted and the holes are improved on the surface (Fig. 2b). When an external potential equal to $E_{\mathrm{fb}}$ is applied, the bands are flat and all charge carriers are annihilated by recombination (Fig. 2a). Under illumination, the photogenerated holes on the SC surface will promote the oxidation of reduced molecules (RED) in which the formal potential is found to be more negative than the valence band of the SC (Fig. 2c) [18, 21, 25, 29]. Figure 3 shows different $\mathrm{SCs}$ and their respective potentials of valence and conduction bands. $\mathrm{TiO}_{2}$ is an n-type semiconductor, which is the most widely used photocatalyst not only for their availability, low cost, and nontoxicity, but also because it has enough valence band potential for the oxidation of $\mathrm{H}_{2} \mathrm{O} / \mathrm{OH}^{-}$ to hydroxyl radicals.

Figure 4 illustrates a summarized scheme for photoelectrocatalytic oxidation using an n-type SC (a) and the photoelectrocatalytic reduction in a p-type semiconductor (b). Photogenerated holes on the SC surface unleash oxidation reactions and electrons are flown through the counter electrode where reduction reactions occur. Therefore, the recombination of charges is minimized and the quantum yield of the photocatalytic process is improved.

For p-type semiconductors, such as $\mathrm{CuO}$ for instance, if an external applied potential is more negative than the flat band potential, an inverse n-type SC process occurs. In this case, electrons are enriched on the SC surface and the holes are depleted. Thus, reduction reactions occur in the photocatalyst (called photocathode), while oxidation reactions take place on the counter electrode $[21,25]$. Figure 5 shows the band bending in a p-type SC and Fig. 4b shows the summarized mechanism for photoelectrocatalytic reduction.
The great versatility of semiconductor materials and the possibility of generating electrons, holes, hydroxyl radicals, and/or superoxide radicals have dramatically increased the application of photoelectrocatalysis over the last years. Considering all the underlying advantages of the technique, it is undoubtedly relevant to outline at least the main important aspects related to the wastewater treatment, in which hydroxyl radical has contributed to the partial or almost complete mineralization of hazardous pollutants. Within this context, it is also essentially important to present a critical analysis on the progress of application in water disinfection and hydrogen generation.

\section{Photoelectrocatalytic Oxidation of Pollutants}

The use of chemicals in the contemporary world is an integral part of daily life involving around 11 million synthetic chemicals, of which 3000 are produced on a large scale, generating a large amount of pollutants with toxic potential released into the environment. The industrial production and the use of these products have a huge impact on the economy, jobs, and global trade. However, beyond the benefits brought by these compounds, there also lies a major concern regarding the presence of these substances in various aquatic environments. It is known that some of these pollutants are responsible for the increased incidence of cancer and birth defects and neurological and hormonal disorders and may lead to the changing of our ecosystems, contaminating water, and food, to mention only a few [30, 31].

The high population growth as well as the expansion of industrial activities in the world is still responsible for the dramatic growth in water consumption, while the supply of drinking water remains constant. By virtue of that, there is an increasing concern vis-à-vis the treatment of waste arising from activities on surface waters, industrial effluents, and wastewater population. 


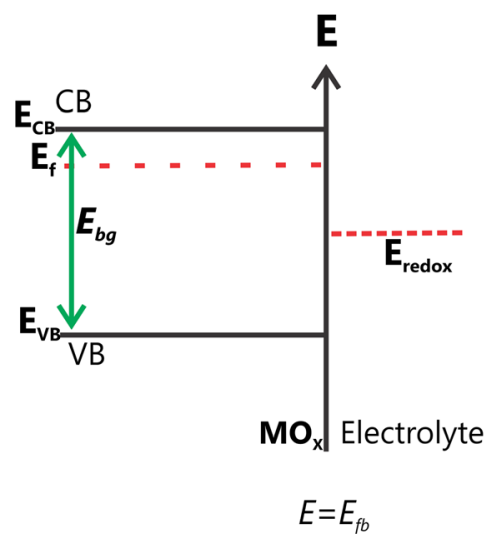

(a)

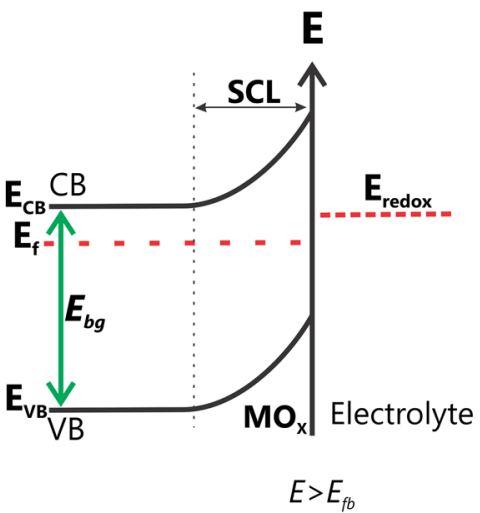

(b)

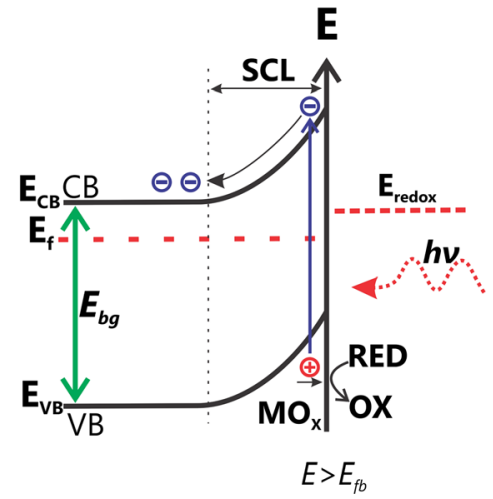

(c)

Fig. 2 Band bending when an n-type SC is under $\mathbf{a} E=E_{\mathrm{fb}}, \mathbf{b} E>E_{\mathrm{fb}}$, and $\mathbf{c} E>E_{\mathrm{fb}}$ and irradiated by light with $\mathrm{h} v \geq E_{\mathrm{bg}}$

The search for efficient methods to promote both color removal and the mineralization of organic compounds has led to a huge interest in the use of photoelectrocatalytic oxidation to treat organic pollutants since the early 1990s [26, 32-34]. There are several photocatalysts applied in photoelectrocatalysis, among them include $\mathrm{TiO}_{2}, \mathrm{WO}_{3}$, $\mathrm{ZnO}, \mathrm{CdS}, \mathrm{Fe}_{2} \mathrm{O}_{3}$, and $\mathrm{SnO}_{2}$. Interestingly, $\mathrm{TiO}_{2}$ has become one of the most successful materials used in general [35] as a result of it being environmentally friendly, having lower cost, long lifetime of electron/hole pairs, compatible energy position of $\mathrm{BV}$ and $\mathrm{BC}$, good chemical and thermal stability, and superior catalytic stability $[2,35]$. Among these characteristics, the band-edge positions relative to $\mathrm{H}_{2} \mathrm{O}$ oxidation are the main property that allows the generation of hydroxyl radicals, as a potent oxidant for the degradation of hazardous contaminants in water.

Photoelectrocatalysis can be said to be a technique belonging to the advanced oxidation processes (AOPs), which are advanced methods for degrading pollutants, based on the generation of hydroxyl radicals $\left({ }^{\bullet} \mathrm{OH}\right)$, which are nonselective and highly oxidizing species capable of mineralizing organic compounds. The core function of the method lies in the irradiation of the SC with light of energy greater than its $E_{\mathrm{bg}}$, responsible for the generation of electron/hole pair $\left(\mathrm{e}^{-} / \mathrm{h}^{+}\right)(\mathrm{Eq}$. 1). The oxidizing nature of the hole $\left(\mathrm{h}^{+}\right)$in the valence band produces - $\mathrm{OH}$ radicals through the oxidation of $\mathrm{H}_{2} \mathrm{O}$ molecules or $\mathrm{OH}^{-}$ ions adsorbed on the semiconductor surface (Eqs. 3 and 4) and is also able to oxidize organic molecules directly (Eq. 5).
Fig. 3 Energy positions of conduction band (CB) and valence band $(\mathrm{VB})$ of selected SC used in photoelectrocatalysis

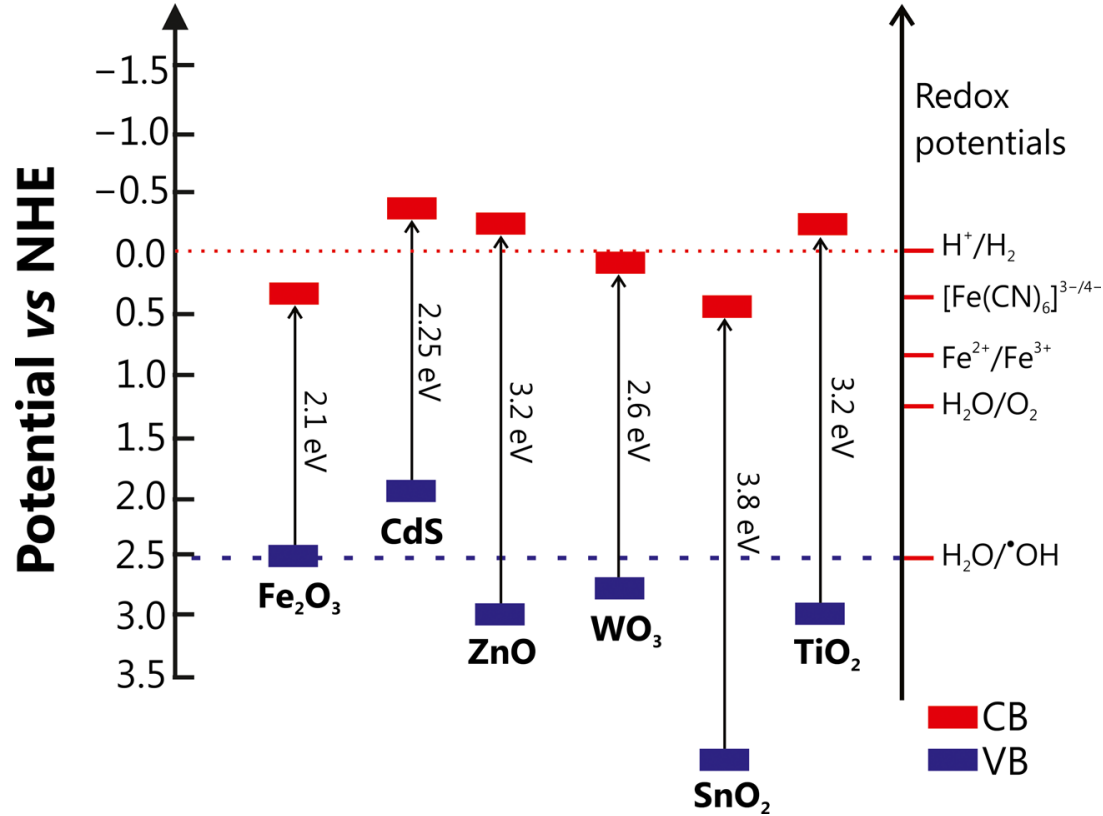


Fig. 4 Mechanism of photoelectrocatalysis and the main reactions for a n-type semiconductor and $\mathbf{b}$ p-type semiconductor

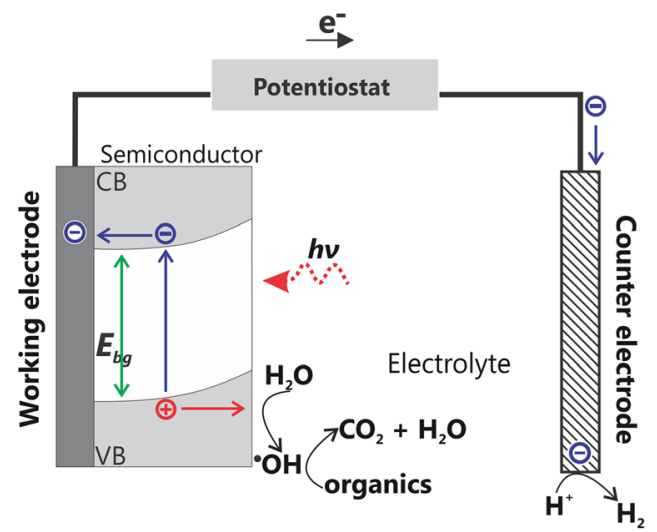

(a)

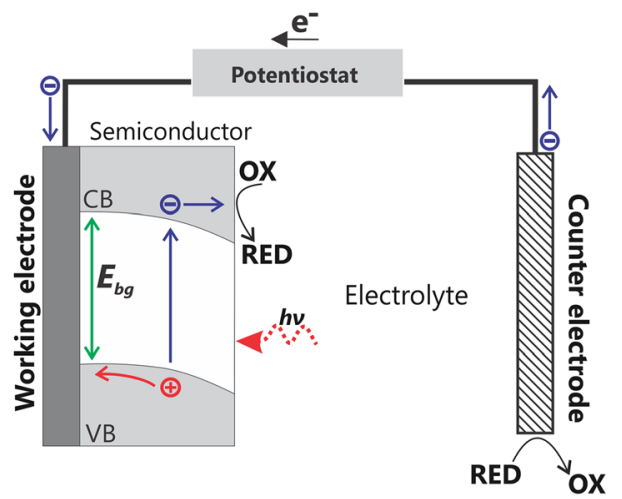

(b)
Anode:

$$
\begin{aligned}
& \mathrm{MO}_{X}-\mathrm{h}_{\mathrm{VB}}^{+}+\mathrm{H}_{2} \mathrm{O}_{\mathrm{ads}} \rightarrow \mathrm{MO}_{X}-\mathrm{HO}_{\mathrm{ads}}^{\bullet}+\mathrm{H}^{+} \\
& \mathrm{MO}_{X}-\mathrm{h}_{\mathrm{VB}}^{+}+\mathrm{HO}_{\mathrm{ads}}^{-} \rightarrow \mathrm{MO}_{X}-\mathrm{HO}_{\mathrm{ads}}^{\cdot} \\
& \mathrm{MO}_{X}-\mathrm{h}_{\mathrm{VB}}^{+}+\mathrm{RX}_{\mathrm{ads}} \rightarrow \mathrm{MO}_{X}+\mathrm{RX}_{\mathrm{ads}}^{\cdot+}
\end{aligned}
$$

Cathode:

$\mathrm{H}_{2} \mathrm{O}+\mathrm{e}^{-} \rightarrow \frac{1}{2} \mathrm{H}_{2}+\mathrm{OH}^{-}$

In the photoelectrocatalysis, photogenerated electron-holes $\left(\mathrm{e}^{-} / \mathrm{h}^{+}\right)$are separated by gradient potential improving the efficiency of the method, since the photogenerated electrons are flown through an external circuit to the counter electrode (Fig. 4a).

The first studies presented good photoactivity for $\mathrm{TiO}_{2}$ thin films acting as photoanodes. The photocatalyst can be immobilized on a conductive glass, Ti plate, or Ti mesh as substrates using the sol-gel method or can be produced through the electrochemical oxidation of a Ti plate. Table 1 displays the main results obtained when this kind of electrode is applied in the treatment of textile dyes, pesticides, and pharmaceutical and other emerging contaminants. The results indicate high decolorization and the maximum total organic carbon of $50 \%$ removal [26, 32, 36-50].

In order to maximize the efficiency of photoelectrocatalysis, several studies were carried out aiming at overcoming two major limitations of $\mathrm{TiO}_{2}$ as photocatalyst: (a) low quantum efficiency due to the recombination of the pair $\mathrm{e}^{-} / \mathrm{h}^{+}$(that might be circumvented by the use of photoelectrocatalysis) and (b) $\mathrm{TiO}_{2}$ is only photoactivated with UV radiation, of $\lambda<387 \mathrm{~nm}$, restricting the use of solar radiation in its application. Therefore, the main goal was to use nanostructured materials to prepare $\mathrm{TiO}_{2}$ and/or doped them with different materials, which will be further discussed in this work.

\section{Nanostructured Morphologies of $\mathrm{TiO}_{2}$ Photoelectrodes}

Advances in photoelectrocatalysis are directly related to advances in materials science, the aim being the achievement of more photoactive, visible, responsive, and stable materials. Thus, with the advent of nanotechnology, more efficient electrodes were developed with the use of nanostructured semiconductor morphologies. Nanostructured photoanodes have

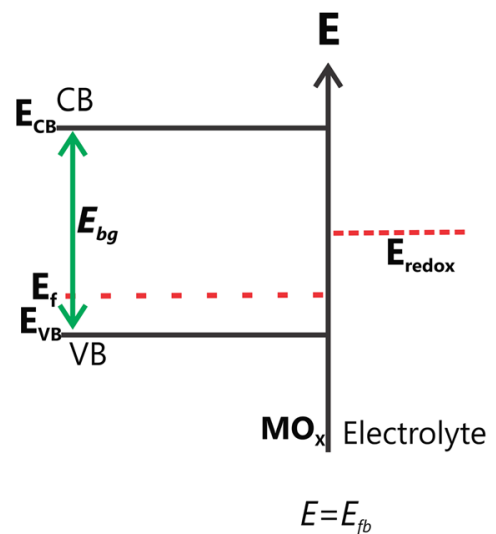

(a)

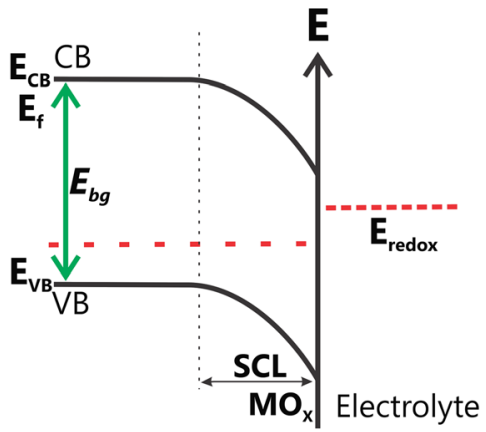

(b)

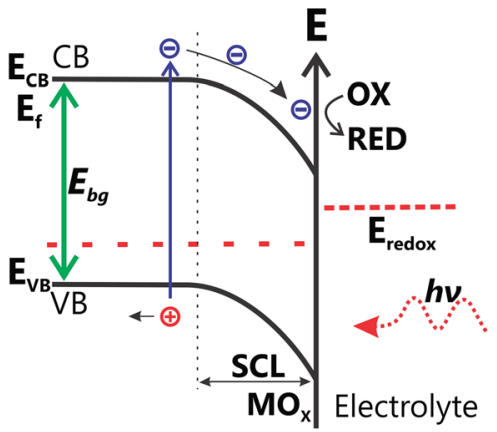

$E<E_{f b}$

(c)

Fig. 5 Band bending when a p-type SC is under $\mathbf{a} E=E_{\mathrm{fb}}, \mathbf{b} E<E_{\mathrm{fb}}$, and $\mathbf{c} E<E_{\mathrm{fb}}$ and irradiated by light with $\mathrm{h} v \geq E_{\mathrm{bg}}$ 
Table 1 Photoelectrocatalytic degradation using $\mathrm{TiO}_{2}$ thin films on conductive substrate and the main findings of these works

\begin{tabular}{|c|c|c|c|}
\hline $\begin{array}{l}\text { Features of thin film } \\
\text { photoanodes }\end{array}$ & Degraded compound & Remarks & Reference \\
\hline $\begin{array}{l}\mathrm{TiO}_{2} \mathrm{P} 25 \text { powder on } \\
\text { conductive glass }\end{array}$ & $\begin{array}{l}\text { 4-Chlorophenol and acid } \\
\text { orange } 7 \text { dye }\end{array}$ & $\begin{array}{l}\text { When } \mathrm{TiO}_{2} \text { thin film electrode was coupled to } \mathrm{SnO}_{2} \text {, there was } \\
\text { enhanced charge separation }\end{array}$ & {$[26,36]$} \\
\hline $\begin{array}{l}\mathrm{TiO}_{2} \text { sol-gel on conductive } \\
\text { glass }\end{array}$ & Formic acid & $\begin{array}{l}\text { PEC oxidation maintains high efficiency even in the absence of } \\
\mathrm{O}_{2} \text { and in the presence of interfering ions }\end{array}$ & {$[32]$} \\
\hline $\mathrm{P} 25 \mathrm{TiO}_{2}$ on FTO glass & Amino acids and derivatives & $\begin{array}{l}\text { The authors evaluated the degradation products and detected that } \\
\text { amino acids are decomposed in } \mathrm{NO}_{3}^{-}, \mathrm{NH}_{4}^{+} \text {, and } \mathrm{CO}_{2}\end{array}$ & {$[37]$} \\
\hline $\begin{array}{l}\mathrm{TiO}_{2} \text { sputter deposited on } \\
\text { conductive glass }\end{array}$ & 4-Chlorophenol & $\begin{array}{l}\text { When using single-compartment cell, it resulted in higher } \\
\text { degradation kinetics compared to double-compartment }\end{array}$ & {$[38]$} \\
\hline $\begin{array}{l}\text { Anodization of meshed } \mathrm{Ti} \\
\text { (thin film) }\end{array}$ & Rose Bengal dye & $\begin{array}{l}\text { The authors compared } \mathrm{PEC} \text { with } \mathrm{PC} \text { using } \mathrm{TiO}_{2} \text { powder; } \mathrm{PEC} \\
\text { oxidation was faster than the } \mathrm{PC} \text { oxidation with } \mathrm{TiO}_{2} \text { concentration } \\
\text { below } 0.3 \%\end{array}$ & {$[39]$} \\
\hline $\begin{array}{l}\text { Anodization of meshed } \mathrm{Ti} \\
\text { (thin film) }\end{array}$ & Humic acid & The addition of sodium peroxodisulfate enhances the degradation & {$[40]$} \\
\hline $\mathrm{TiO}_{2}$ sol-gel on $\mathrm{Ti}$ & $\begin{array}{l}\text { Remazol Brilliant Orange } \\
\text { 3R dye }\end{array}$ & The use of chloride ion electrolyte provides high decolorization rate & {$[41]$} \\
\hline $\mathrm{TiO}_{2}$ sol-gel on Ti plate & $\begin{array}{l}\text { Metallophtalocyanine } \\
\text { (reactive turquoise blue } \\
15 \text { dye) }\end{array}$ & $\begin{array}{l}\text { The authors achieved } 95 \% \text { of mineralization and } 69 \% \text { of copper } \\
\text { removal on the cathode }\end{array}$ & {$[42]$} \\
\hline $\begin{array}{l}\text { Anodization of Ti plate } \\
\text { (thin film) }\end{array}$ & Pentachlorophenol & $\begin{array}{l}\text { The authors compared the thin film electrode with } \mathrm{TiO}_{2} \mathrm{NTs} \text {, which } \\
\text { enhances the degradation }\end{array}$ & {$[43]$} \\
\hline $\mathrm{P} 25 \mathrm{TiO}_{2}$ on Ti plate & Imidacloprid & $\begin{array}{l}\text { PEC oxidation leads to an increase of } 249 \% \text { in the apparent rate } \\
\text { constant compared to the PC process }\end{array}$ & {$[44]$} \\
\hline $\mathrm{TiO}_{2}$ sol-gel on graphite rods & 4-Nitrophenol degradation & The authors constructed a continuous annular PEC reactor & {$[45]$} \\
\hline $\mathrm{TiO}_{2}$ sol-gel on Ti plate & Simulated tannery effluent & $\begin{array}{l}\text { The authors reached } 100 \% \text { decolorization, } 100 \% \text { surfactant removal, } \\
\text { and around } 100 \% \mathrm{Cr}(\mathrm{VI}) \text { reduction }\end{array}$ & [46] \\
\hline $\mathrm{TiO}_{2}$ sol-gel on Ti plate & $\begin{array}{l}\text { Disperse dyes from a textile } \\
\text { industry }\end{array}$ & $\begin{array}{l}\text { PEC leads to up to } 69 \% \text { of COD and } 50 \% \text { TOC reduction and } 89 \% \\
\text { decolorization }\end{array}$ & {$[47]$} \\
\hline $\mathrm{TiO}_{2}$ sol-gel on Ti plate & Indigo carmine dye & $\begin{array}{l}\text { The authors applied controlled current instead of the constant potential } \\
\text { in PEC oxidation }\end{array}$ & {$[48]$} \\
\hline $\mathrm{TiO}_{2}$ sol-gel on ITO & Bisphenol A & $\begin{array}{l}\text { The authors used solar PEC system and also verified that the use } \\
\text { of BDD cathode enhances the formation of reactive species }\end{array}$ & [49] \\
\hline $\mathrm{TiO}_{2}$ sol-gel on Ti plate & Nickel (II)-EDTA & $\begin{array}{l}90 \% \text { of the complex is removed and nickel can be recovered }(45 \%) \\
\text { from the cathode as } \mathrm{Ni}^{0}\end{array}$ & {$[50]$} \\
\hline
\end{tabular}

mainly two advantages over thin films: (i) high surface area (this improves reaction/interaction between the material and interacting media) and (ii) efficient charge transfer, reducing electron-hole recombination [18].

Recently, a great number of investigations focused on the photoelectrocatalytic properties of $\mathrm{TiO}_{2}$ nanomaterials and effective ways to improve their efficiency have been reported, and various nanostructures [18] such as nanopores [51], nanowires [52-54], nanorods [55-57], and nanotubes [35, 58, 59] were produced. However, among these several $\mathrm{TiO}_{2}$ morphologies, titanium dioxide nanotube arrays $\left(\mathrm{TiO}_{2} \mathrm{NTs}\right)$ have received a remarkable interest because they exhibit excellent stability, large internal surface area, and excellent electron percolation pathways for vectorial charge transfer. Among the different methods related to the preparation of $\mathrm{TiO}_{2}$ nanotubes $\left(\mathrm{TiO}_{2} \mathrm{NTs}\right)$ and other $\mathrm{TiO}_{2}$ nanostructured materials [60-62], the use of electrochemical anodization of Ti plate presents an easy production way capable of controlling the growth properties and dimensions of $\mathrm{TiO}_{2} \mathrm{NTs}[18,35,54$,
$58,59,63,64]$. The preparation basically involves the connection of a cleaned Ti plate to the positive pole (anode) of a dc power supply and a counter electrode (usually $\mathrm{Pt}$ ) that is connected to the negative pole (cathode). The electrodes are placed in an electrolytic solution containing fluoride ions, and when a potential is applied in the system, the metal reacts with oxygen ions from the electrolyte growing in the oxide film on the surface (growing on the oxide film surface). $\mathrm{TiO}_{2} \mathrm{NTs}$ can be produced with adjustments of electrolyte composition, applied potential, and anodization time. Due to their unique properties, $\mathrm{TiO}_{2} \mathrm{NTs}$ have been used in many applications such as in photo(electro)catalysis [4, 5, 65, 66], sensors [67, 68], biosensors [69], dye-sensitized solar cells [70, 71], hydrogen generation by water photoelectrolysis [72-74], photocatalytic reduction of $\mathrm{CO}_{2}[58,75]$, and biomedical-related applications [76, 77]. Table 2 illustrates some works aimed at nanostructured materials applied in the treatment of endocrine disruptors, pharmaceutical compounds, aromatic amines, ammonia, and sunscreen compounds. The removal of 


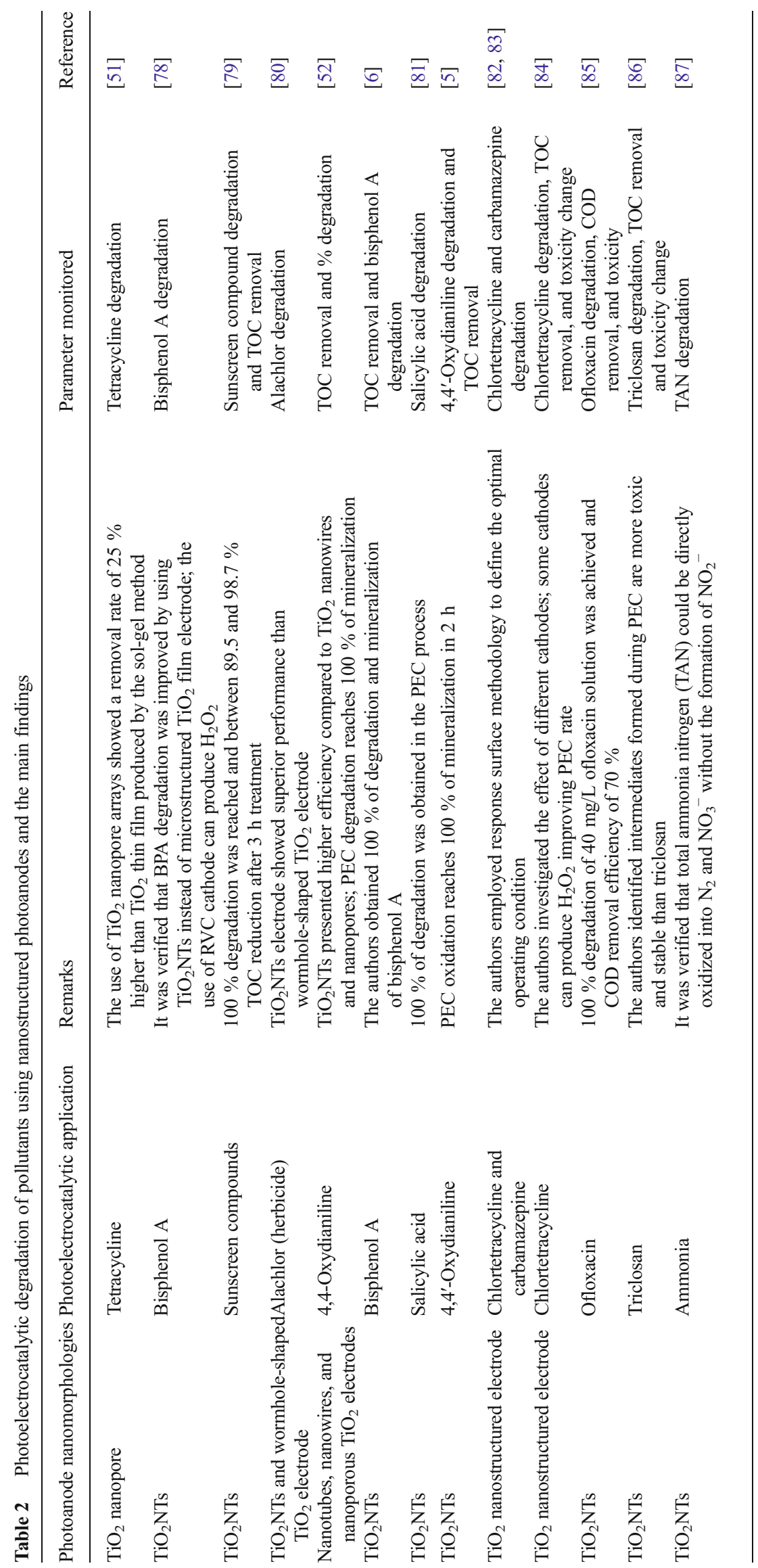


tetracycline, bisphenol A, alachlor, and 4,4-oxydianiline is markedly increased when nanostructured materials are compared to non-nanostructured materials $[51,52,78,80]$.

The influence of structural and surface morphology of $\mathrm{TiO}_{2}$ has been reported in the photoelectrocatalytic oxidation of 4 , 4-oxydianiline (ODAN). The electrolyte played an important role in the preparation of $\mathrm{TiO}_{2}$ nanotubes and $\mathrm{TiO}_{2}$ nanowires which are preponderantly formed by electrochemical anodization of Ti foil in glycerol/ $\mathrm{NH}_{4} \mathrm{~F} /$ water, $30 \mathrm{~V} / 20 \mathrm{~h}$ and $\mathrm{DMSO} / \mathrm{HF}, 30 \mathrm{~V} / 20 \mathrm{~h}$, respectively. Both presented higher photocurrent compared to $\mathrm{TiO}_{2}$ nanoporous electrode prepared by the sol-gel method. Although $\mathrm{TiO}_{2}$ nanowires presented higher photoactivity than nanotubes, when applied in the degradation of ODAN, it reached $100 \%$ total organic carbon (TOC) removal after 120 min of treatment on $\mathrm{TiO}_{2} \mathrm{NT}$ electrodes, while only 68 and $47 \%$ are obtained in nanowires and nanoporous morphologies, respectively. These results attest to the fact that the ordered nanotube arrays stand as the most favorable when it comes to the transport of photogenerated electrons in the $\mathrm{TiO}_{2}$ film, which is very important in the photoelectrocatalytic (PEC) process. $\mathrm{TiO}_{2} \mathrm{NT}$ photoanodes present electron vectorial channel transportation through the tube walls, thereby increasing the lifetime of photogenerated holes which in turn dramatically improves the degradation rate of aromatic amines [5]. A similar behavior is observed when wormhole-shaped $\mathrm{TiO}_{2}$ are compared with nanotube-shaped $\mathrm{TiO}_{2}$ photoelectrodes applied in the photoelectrocatalytic degradation of alachlor herbicide. The degradation rate of alachlor was found to increase from $59 \%$, in the wormhole $\mathrm{TiO}_{2}$ electrodes to $94 \%$ on $\mathrm{TiO}_{2} \mathrm{NT}$ photoelectrodes [80].

Another advantage that stems from the preparation of $\mathrm{TiO}_{2} \mathrm{NTs}$ by electrochemical anodization lies in the precise control of tube dimensions $[25,58]$. As we know from the literature [88], there is a direct dependence of $\mathrm{TiO}_{2}$ nanotube array length in the photoelectrocatalytic activity. This can be explained because the increased length of the tubes will increase the resistance of the $\mathrm{TiO}_{2} \mathrm{NTs}$, which reduces the intensity of the electric field within the $\mathrm{TiO}_{2}$ and decreases the charge separation. Furthermore, in a long nanotube array, the photogenerated electrons have an increased probability of recombination due to the increased distance through the nanotubes to the substrate. Table 2 shows a compilation of photoelectrocatalytic degradation of pollutants using nanostructured photoanodes.

\section{Doped and Surface-Modified $\mathrm{TiO}_{2}$ Photoanodes}

In order to minimize the costs of photoelectrocatalysis in the treatment of hazardous compounds, huge advances have been made in the search for more photoactive materials using nanostructured semiconductors capable of being more active under visible light irradiation. Taking into consideration that UV irradiation corresponds to around $5 \%$ of the sunlight, efforts have been geared toward making $\mathrm{TiO}_{2}$ responsive to visible light by using doping (anion and/or cation) or surface decoration with noble metals or coupling with other semiconductors with small band gap energy. The modification of optical properties of semiconductors has been termed in the literature as band gap engineering $[18,54,63]$.

$\mathrm{TiO}_{2}$ doping with anions or cations, which is called secondgeneration photocatalysts [89], has been carried out successfully in order to obtain more photoactive materials and more responsiveness in the visible region of the spectrum. Some researchers have proposed that anion doping shifts the absorption edge of $\mathrm{TiO}_{2}$ to lower energies through the narrowing of the $\mathrm{TiO}_{2}$ band gap. However, some works have proposed that a doped $\mathrm{TiO}_{2}$ presents electronic transitions from localized states in the band gap to the conduction band of the semiconductor. Other proposition for the red shift of the absorption edge is linked to the formation of color centers, which include $\mathrm{Ti}^{3+}$ centers and oxygen vacancies [89]. Although there are several propositions aimed at explaining the reason for the red shift, it is not possible to clearly work out the role of dopants, and as such, no consensus has been reached on that in the scientific community [17, 25, 89].

Table 3 summarizes some examples of $\mathrm{TiO}_{2}$ photoanodes subjected to doping, surface decoration, and composite formation demonstrating shifts in the absorption edge of $\mathrm{TiO}_{2}$. It is accepted that nitrogen-doped $\mathrm{TiO}_{2}$ photoanodes present a band gap decrease from 3.2 to $2.3 \mathrm{eV}[82,90]$ applied in the chlortetracycline degradation [82]. Boron-doped $\mathrm{TiO}_{2} \mathrm{NTs}_{\text {are }}$ photoactive under visible light absorption and promote high oxidation of Acid Yellow 1 dye and phenol, when treated by photoelectrocatalysis $[4,91]$.

It is well known that $\mathrm{TiO}_{2}$ doped with metal, such as $\mathrm{W}$ [92], $\mathrm{Cr}$ [93], $\mathrm{Zr}$ [94, 103], and $\mathrm{Fe}$ [104], can form new energy states either within or beyond the VB and $\mathrm{CB}$, decreasing the band gap energy. However, transition metals may also act as recombination sites and may cause thermal instability to the anatase phase of $\mathrm{TiO}_{2}[17,24]$. Gong et al. [92] prepared tungsten-doped $\mathrm{TiO}_{2} \mathrm{NTs}\left(\mathrm{W}-\mathrm{TiO}_{2} \mathrm{NTs}\right)$ by electrochemical anodization and have illustrated that the band gap energies decreased from $\sim 3.18$ to $\sim 2.97 \mathrm{eV}$. These photoanodes were applied in PEC degradation of RhB dye and doped electrodes showed higher efficiency compared to the undoped ones. Other studies involving $\mathrm{Cr}$-doped $\mathrm{TiO}_{2} \mathrm{NTs}$ showed enhanced efficiency in the degradation of $p$-nitrophenol [93].

Another approach reported in the literature is focused on the incorporation of more than one anion and/or cation into the structure of $\mathrm{TiO}_{2}$, which is called codoping. N/Zr-codoped $\mathrm{TiO}_{2}$ nanotube arrays increased photoactivity under UV and visible light and were applied in the PEC oxidation of 4,4'dibromobiphenyl showing improved PEC efficiency [94].

The preparation of compound semiconductors was carried out by the coupling of two semiconductors with appropriate 


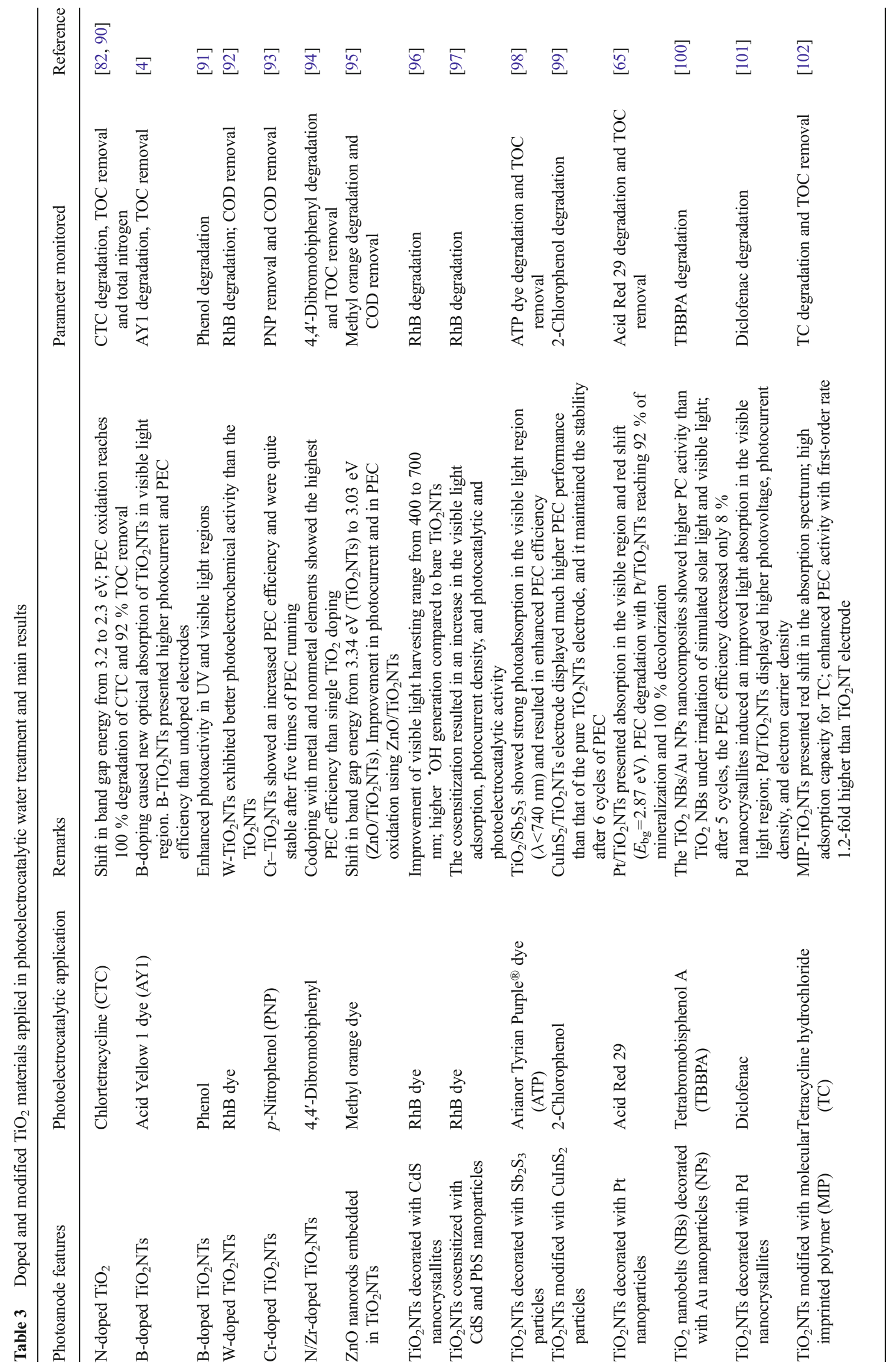


$\mathrm{CB}$ and $\mathrm{CV}$ energy, aiming at $\mathrm{e}^{-} / \mathrm{h}^{+}$pair recombination reduction due to the transfer of carriers from one semiconductor to the other, as can be seen in Fig. 6. Furthermore, depending on the band gap energy of the semiconductor used, the compound can be activated in the visible region [17]. CdS is the most reported semiconductor used in coupling with $\mathrm{TiO}_{2}$ due to its small band gap energy $\left(E_{\mathrm{bg}}=2.4 \mathrm{eV}\right)$ [96], with great performance in the dye degradation under visible and UV absorption region. The decoration with deposits of $\mathrm{Sb}_{2} \mathrm{~S}_{3}$ by chemical bath deposition showed a higher photocurrent as opposed to bare $\mathrm{TiO}_{2} \mathrm{NTs}$ and improved PEC degradation rate in the treatment of hair dye solution [98]. Modified $\mathrm{TiO}_{2}$ nanotube arrays with $\mathrm{CuInS}_{2}$ presented a band gap of $1.5 \mathrm{eV}$, and the compound obtained showed enhanced UV and visible absorption with higher PEC oxidation rate of 2-chlorophenol.

Therefore, the coupling of $\mathrm{WO}_{3}$ to $\mathrm{TiO}_{2}$ has been highlighted and their use for the photoelectrocatalytic oxidation of organic species (both in solution and gas phase) has also been thoroughly reviewed [27]. The bicomponent oxides are semiconductors with a band gap energy $\left(E_{\mathrm{bg}}\right)$ in the range of 2.5$3.2 \mathrm{eV}$, although $\mathrm{WO}_{3}$ presents lower $E_{\mathrm{bg}}(2.5-2.8 \mathrm{eV})$ values compared to $\mathrm{TiO}_{2}(3.0$ to $3.2 \mathrm{eV})$ [27]. By virtue of that, tungsten can be activated by wavelengths in the visible range (greater than $380 \mathrm{~nm}$ ), allowing the use of solar radiation (hv) as energy source. In the compound, $\mathrm{TiO}_{2}$ provides additional properties and, thus, may serve as electron acceptor species from the separation of charges $\left(\mathrm{e}^{-} / \mathrm{h}^{+}\right)$for example. Consequently, this may enlarge the number of holes onto $\mathrm{TiO}_{2}$ surface and increase the flow of electrons to the counter electrode against photoelectrocatalytic conditions and thus improve the efficiency. The compound films also demonstrated to be photocatalytically more active than the array of individual $\mathrm{WO}_{3}$ or $\mathrm{TiO}_{2}$ [27]. This behavior can be explained as

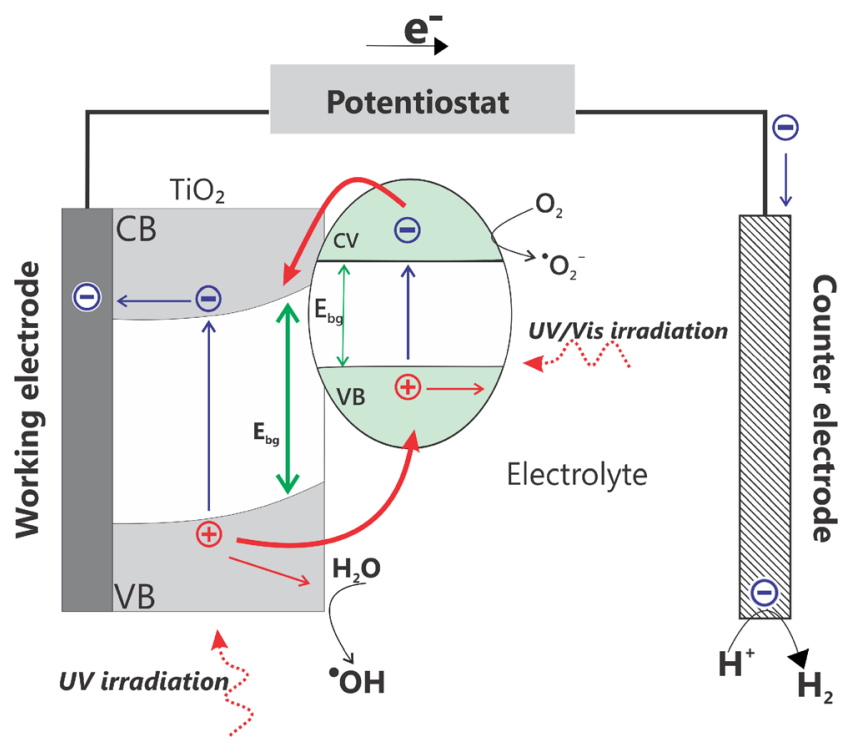

Fig. 6 Schematic representation of the photoelectrocatalytic mechanism of $\mathrm{TiO}_{2}$ coupled to visible responsible semiconductor stemming from the photoexcited electron transfer from the $\mathrm{WO}_{3}$ particles to $\mathrm{TiO}_{2}$ (Fig. 6). These compounds could be used in new technology involving the degradation of organic contaminants by using sunlight, making it economically attractive. The use of bicomponent nanostructured $\mathrm{TiO}_{2} / \mathrm{WO}_{3}$ electrode prepared by the template method promoted $97 \%$ of decolorization of the indigo carmine dye and $62 \%$ of mineralization under applied potential of $1.0 \mathrm{~V}$ under visible light irradiation [105]. The literature reports some works involving photoelectrocatalytic oxidation of organic compounds using bicomposites of $\mathrm{TiO}_{2} / \mathrm{WO}_{3}[106-110]$.

Another technique reported with the aim of improving photoelectrocatalytic efficiency is the decoration of $\mathrm{TiO}_{2}$ surface with noble metal particles, such as $\mathrm{Ag}, \mathrm{Au}, \mathrm{Pt}$, and $\mathrm{Pd}$. When a semiconductor and metal particle are in contact, a Schottky barrier can be formed in the new material due to different Fermi levels of $\mathrm{TiO}_{2}$ and the metal nanoparticles. Therefore, there is a rectification of charge carrier transfer where the energetic difference at the semiconductor/metal interface drives the excited $\mathrm{e}^{-}$from the $\mathrm{CB}$ of $\mathrm{SC}$ to the metal nanoparticles. In other words, the metallic particle acts as an electron trap minimizing the recombination of the $\mathrm{e}^{-} / \mathrm{h}^{+}$pair and improving photoelectrocatalytic efficiency, as shown in Fig. 7 [17].

Pt nanoparticles deposited on $\mathrm{TiO}_{2} \mathrm{NTs}$ [65] led to a decrease in the band gap energy of $\mathrm{TiO}_{2} \mathrm{NTs}$ from $3.21 \mathrm{eV}$ $\left(\mathrm{TiO}_{2} \mathrm{NTs}\right)$ to $2.87 \mathrm{eV}\left(\mathrm{Pt} / \mathrm{TiO}_{2} \mathrm{NTs}\right)$, dramatically increasing the kinetics of degradation of an acid dye. Table 3 indicates some works dealing with $\mathrm{TiO}_{2}$ nanobelts $\left(\mathrm{TiO}_{2} \mathrm{NBs}\right)$ electrode decorated with $\mathrm{Au}$ nanoparticles by electrodeposition [100], and $\mathrm{Pd}$ nanocrystallite-decorated $\mathrm{TiO}_{2}$ nanotubes $(\mathrm{Pd} /$ TNTs) [101] displayed an absorption region ranging from 540 and $700 \mathrm{~nm}$ and higher PEC performance when applied in the degradation of diclofenac.

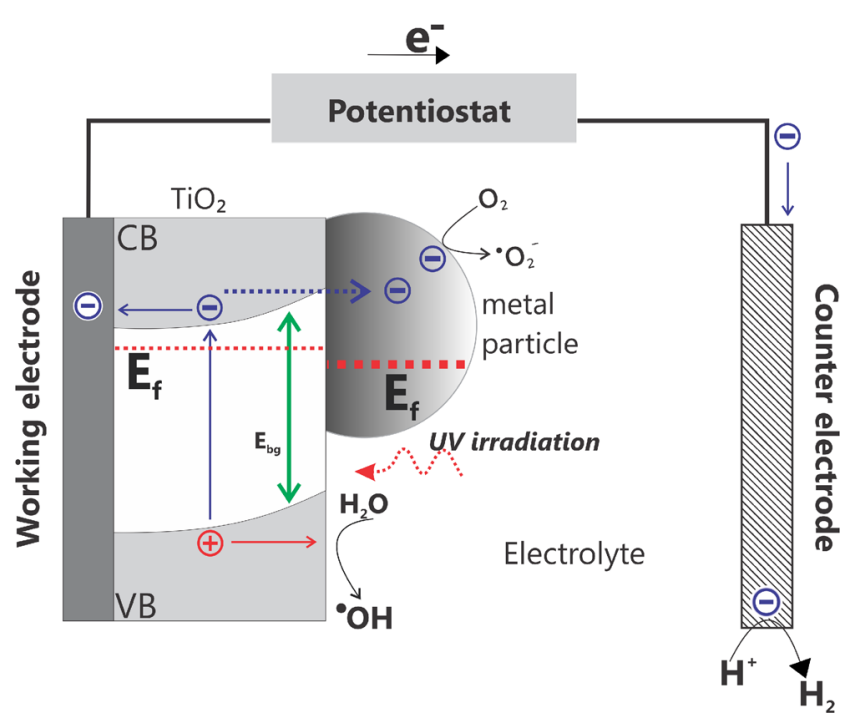

Fig. 7 Schematic depiction of the photoelectrocatalytic mechanism of $\mathrm{TiO}_{2}$ coupled to a metal particle 
In addition to the different types of modification/doping mentioned above, there are other strategies used to improve the photoelectrocatalytic efficiency of $\mathrm{TiO}_{2}$ materials reported in the literature: (i) immobilization of organic compounds onto $\mathrm{TiO}_{2}$ surface such as salicylic acid [111] acting as an acceptor of photogenerated holes; (ii) dye sensitization of $\mathrm{TiO}_{2}$ surface [112], in order to extend the light absorption of $\mathrm{TiO}_{2}$ to a visible region; (iii) self-doping of $\mathrm{Ti}^{3+}$ into $\mathrm{TiO}_{2}$ [113], resulting in increased electrical conductivity and visible light absorption; (iv) coupling with more conductive compounds, such as polyaniline [93] and carbon nanotubes [114]; and (v) modification with molecular imprinted polymer (MIP) [102] in order to improve adsorption of a specific contaminant.

\section{Reactions Occurring in the Counter Electrode (Cathode)}

In a typical photoelectrochemical cell using $\mathrm{TiO}_{2}$ as photoanode and platinum as cathode, electron/hole pairs are generated under the incidence of UV light. Owing to the electric field generated as a function of applied potential, the photogenerated holes with high oxidizing power reach the semiconductor surface more readily and electrons are directed to the cathode via external electric circuit. In an idealized situation, it would be possible to oxidize organic species in the photoanode besides water (Eq. 6). Thus, the electrodes could be suitable for both photoelectrocatalysis and simultaneous electrochemical reduction on the cathode.

Several cathode types have been explored, including carbonaceous materials [84] (such as graphite, vitreous carbon, carbon felt) [78], oxygen diffusion cathodes [115], and borondoped diamond electrode [49], which can be used for satisfactory electrochemical production of $\mathrm{H}_{2} \mathrm{O}_{2}$. In a PEC system, $\mathrm{H}_{2} \mathrm{O}_{2}$ can act as electron acceptor, thus preventing the recombination of $\mathrm{e}^{-} / \mathrm{h}^{+}$pairs and causing decomposition into hydroxyl radicals $\left(\mathrm{H}_{2} \mathrm{O}_{2}+\mathrm{e}_{\mathrm{CB}}^{-} \rightarrow \mathrm{OH}^{-}+{ }^{\bullet} \mathrm{OH}\right)$. Due to the instability and risk involved in the transportation and storage of $\mathrm{H}_{2} \mathrm{O}_{2}$, it can be produced by the cathodic reduction of oxygen on the counter electrode [116] in acid solutions (Eq. 7) and in alkaline solutions (Eq. 8):

$$
\begin{aligned}
& \mathrm{O}_{2}+2 \mathrm{H}^{+}+2 \mathrm{e}^{-} \rightarrow \mathrm{H}_{2} \mathrm{O}_{2} \\
& \mathrm{O}_{2}+2 \mathrm{H}_{2} \mathrm{O}+2 \mathrm{e}^{-} \rightarrow \mathrm{H}_{2} \mathrm{O}_{2}+2 \mathrm{OH}^{-}
\end{aligned}
$$

From what we know in the literature [116], $\mathrm{H}_{2} \mathrm{O}_{2}$ production is favored on graphite $>\mathrm{Ag}>\mathrm{Pt}>\mathrm{ITO}$ glass. Different types of carbonaceous electrodes (stainless steel (SS); graphite (Gr); vitreous carbon (VC); amorphous carbon at 20 and $600{ }^{\circ} \mathrm{C}\left(\mathrm{a}-\mathrm{C} 1\right.$ and a-C2)) have been evaluated [84] for $\mathrm{H}_{2} \mathrm{O}_{2}$ production in a PEC system. Among them, vitreous carbon has proven to be the most efficient material. Daskalaki and collaborators [49] studied $\mathrm{H}_{2} \mathrm{O}_{2}$ generation using borondoped diamond (BDD) cathode and verified that it was 1.7 times more efficient in the PEC oxidation of bisphenol A than zirconium cathode, when the same photoanode is used.

Another interesting feature of PEC systems lies in its ability vis-à-vis the reduction of heavy metals in the cathode. Paschoal and collaborators [46] investigated the simultaneous degradation of organic compounds and the reduction of $\mathrm{Cr}(\mathrm{VI})$ to $\mathrm{Cr}(\mathrm{III})$ in a simulated tannery effluent. The PEC technique reduced around $98-100 \%$ of $\mathrm{Cr}(\mathrm{VI})$ and reached $95 \%$ of TOC removal. Simultaneous degradation of EDTA and the respective Ni-EDTA complex has been published [50], where $45 \%$ has been recovered in the form of $\mathrm{Ni}^{0}$ on the cathode during degradation.

An important aspect of these reactions is the possibility of using photoelectrocatalytic oxidation of organic compounds on the photoanode in order to concomitantly produce hydrogen in the cathode. A deep overview is reported by Lianos [13]. $\mathrm{TiO}_{2}$ electrode (anode) is separated in a twocompartment cell from the counter electrode (cathode) by a Nafion membrane, irradiated by UV light and bias potential, such that oxidation could occur simultaneously on the anode and generate hydrogen on the cathode. The literature reports the use of ethanol, glycerol, and methanol or models of biomass compounds useful in photoelectrochemical incineration on the photoanode [117-119]. When this process occurs in a photoelectrocatalytic cell, a relatively large number of electrons should be conducted through the external circuit to reduce hydrogen ions and produce molecular hydrogen [13].

Recent works have shown that a huge number of organic substances that are considered waste materials or pollutants can be photodegraded to produce hydrogen [120-124]. It is worth pointing out that adding value to the treatment of pollutants and producing hydrogen as an energy source is at the core of this goal.

In this system, solutions containing organic compounds such as reactive black 5 dye in the photoanode compartment could be oxidized due to hydroxyl radicals formed during water oxidation on the $\mathrm{TiO}_{2} \mathrm{NT}$ electrodes (anode) in the neutral electrolyte [14]. When the system is connected to the cathode compartment separated by a Nafion membrane containing Pt electrode immersed in acid medium ( $\mathrm{pH} 4$ ), up to $100 \%$ of color removal and $72 \%$ mineralization of the organic compound are achieved when treated in $0.1 \mathrm{M} \mathrm{Na}_{2} \mathrm{SO}_{4} \mathrm{pH} 6, E=1.0 \mathrm{~V}$ with UV irradiation. Simultaneously, $44 \%$ of hydrogen efficiency was obtained after $2 \mathrm{~h}$ of photoelectrolysis. After photoelectrocatalytic oxidation on the anode, the photogenerated electrons move through the external circuit to the cathode without irradiation where the reduction of protons occurs under anaerobic conditions. Thus, the conversion of the pollutants in $\mathrm{CO}_{2}$ and minerals into energy via hydrogen production [125] is an attractive strategy with double environmental benefit, for instance, the treatment process of wastewater containing undesirable waste 
which lies as the end goal of industries that are seeking low cost methods or higher added value.

\section{Photoelectrocatalytic Disinfection}

Many methods have been proposed for the disinfection of water, using chemical elements such as chlorine, chlorine dioxide, ozone, and ultraviolet radiation. Among them, chlorine is widely used to disinfect drinking water because of its low cost as well as the wide range of available information on it. However, this element can form toxic by-products such as carcinogenic trihalomethanes (THMs); in addition to that, there are some microorganisms that are found to be resistant to chlorine disinfection [126].

The inactivation of microorganism is more complex than the degradation of organic compounds. In the case of organic compounds, only one modification in the structure of an organic molecule leads to its disappearance, while the inactivation of a microorganism does not correspond to only a modification of an organic molecule present in the microorganism [127]. Furthermore, the size of organic molecules is something less than $1 \mathrm{~nm}$, while the size of a microorganism is generally greater than $300 \mathrm{~nm}$. Another important point is that the composition of a microorganism is very complex, being composed of different membranes or layers containing distinct types of organic molecules released during the treatment process.

It is in this light that the development of alternative processes to disinfect drinking water ought to be given the needed attention and boost. Among the alternatives to disinfection, the advanced oxidation process has shown promising results and most especially photoelectrocatalysis. Most of the studies have reported about disinfection by photoelectrocatalysis using Escherichia coli as a model microorganism, as shown in Table 4. Table 4 also outlines a number of other microorganisms and the percentage of disinfection reached with each photoelectrode.

The first application of photoelectrochemical in sterilization was reported by Matsunaga et al. in 1985 [128]. The authors used platinum loaded with titanium oxide, $\mathrm{TiO}_{2} / \mathrm{Pt}$, to inactivate Lactobacillus acidophilus, Saccharomyces cerevisiae, and E. coli $\left(10^{3}\right.$ cells $\left./ \mathrm{mL}\right)$ under UV irradiation during 60-120 min. The photoelectrochemical oxidation of coenzyme A was responsible for the death of the cells. After that, in 1997, Butterfield et al. [129] reapplied the electric field and irradiation to disinfect water containing Clostridium perfringens spores and $E$. coli using immobilized powders of $\mathrm{TiO}_{2}$. The authors reported that the photochemical disinfection does not only eliminate the drawbacks of scouring and mass transport limitation but also enhances hydroxyl radical production. But using a current density of $300 \mu \mathrm{A} \mathrm{cm}^{-2}$, the reactor removes over $3 \log$ units $(100 \%)$ of $E$. coli and $2 \log$ units of $C$. perfringens spores within $25 \mathrm{~min}$. As shown in
Table 4, the inactivation of $E$. coli has been proposed using different electrodes, such as nanoporous $\mathrm{TiO}_{2}$ electrode [130], $\mathrm{TiO}_{2}$ nanotubes [131], iron-doped $\mathrm{TiO}_{2}$ sol-gel electrode [132], $\mathrm{TiO}_{2}$ film loaded with $\mathrm{Ag}\left(\mathrm{Ag}-\mathrm{TiO}_{2} / \mathrm{G}\right)$ and $\mathrm{Cu}(\mathrm{Cu}-$ $\mathrm{TiO}_{2} / \mathrm{G}$ ) [133], and $\mathrm{TiO}_{2} \mathrm{P} 25$ [135]. The fastest inactivation of E. coli $\left(10^{6} \mathrm{CFU} \mathrm{mL} \mathrm{mL}^{-1}\right)$ was reached after $10 \mathrm{~min}$ of photoelectrocatalytic oxidation on $\mathrm{TiO}_{2} \mathrm{NTs}$ biased with anodic potential of $+3.0 \mathrm{~V}$ vs. SCE [131].

The most commonly accepted photoelectrocatalytic inactivation mechanism involves the attack of ${ }^{\bullet} \mathrm{OH}$ radicals and other reactive oxygen species (ROS) generated during the photoelectrocatalytic process on the bacterial cell wall, where the bacterium and catalyst interact. Cumulative damage disrupts the cell membrane and increases cell permeability, which culminates in cell lysis and death. This means that $\mathrm{TiO}_{2}$ absorbs energy photons with suitable energy relative to an active area of the $\mathrm{Ti} / \mathrm{TiO}_{2}$ electrode, to generate an electron-hole pair. The hole in the valence band can react with $\mathrm{H}_{2} \mathrm{O}$ or hydroxide ions adsorbed on the electrode surface, producing hydroxyl radicals $(\cdot \mathrm{OH})$; the electrons in the conduction band can reduce $\mathrm{O}_{2}$, which yields superoxide ions $\left(\mathrm{O}_{2}{ }^{-}\right)$, or under bias potential, the electrons can be driven to the auxiliary electrode via the external circuit. Both holes and ${ }^{\bullet} \mathrm{OH}$ are extremely reactive and capable of inactivating the microorganism.

The indirect photoelectrocatalytic oxidation is also reported in the medium of chloride [148] or bromide [137, 149], which can generate free chlorine or bromine, respectively, in an open-air reactor using a $\mathrm{TiO}_{2}$ thin film electrode biased at + $1.0 \mathrm{~V}$ (SCE) and illuminated by UV light. Indirect oxidation of chloride to chlorine resulted in $99.9 \%$ E. coli inactivation in $45 \mathrm{~min}$. Following the use of $\mathrm{TiO}_{2}$ photoanode under UVLED array light source, $\left(\lambda_{\max }=365 \mathrm{~nm}\right)$, and $0.1 \mathrm{NaNO}_{3}$ supporting electrolyte and additional $1.0 \mathrm{mM} \mathrm{NaBr}$ under + $0.30 \mathrm{~V}$ vs. $\mathrm{Ag} / \mathrm{AgCl}, 100 \%$ of inactivation of $9 \times$ $10^{6} \mathrm{CFU} \mathrm{mL}^{-1}$ E. coli within $1.57 \mathrm{~s}$ was achieved [149]. The inactivation in the presence of $1.0 \mathrm{mM} \mathrm{Cl}^{-}$was 13 times faster than that of the PEC method in the absence of $\mathrm{Cl}^{-}$. However, the PEC-Br treatment is comparatively about 15 times faster. The superior bactericidal efficiency can be largely attributed to the effectiveness of the photoelectrocatalytically generated new bactericides such as $\mathrm{Br} \bullet$ and $\mathrm{Br}_{2}{ }^{--}$via the reaction of bromide and hydroxyl radicals.

The disinfection of Enterococcus faecalis and E. coli [138] using $\mathrm{TiO}_{2} /$ Ti film anode under simulated solar radiation (UVA and UV-B radiation, $\lambda<280 \mathrm{~nm})$ in the presence of $1 \%(w /$ v) $\mathrm{Na}_{2} \mathrm{SO}_{4}$ aqueous solution was monitored by the cell culture method and at real-time polymerase chain reaction (PCR). Photoelectrocatalysis using lower potential has been proposed by Liu et al. [140] under UV and visible light on a rutile $\mathrm{TiO}_{2}$ photoanode. The inactivation of $1.0 \times 10^{7} \mathrm{CFU} \mathrm{mL}{ }^{-1} E$. coli in $0.10 \mathrm{M} \mathrm{NaNO}_{3}$ under an applied potential of $+0.40 \mathrm{~V}$ and UV irradiation was $99.97 \%$; inactivation occurred within $10 \mathrm{~min}$ and $100 \%$ within 180 min under visible irradiation. 


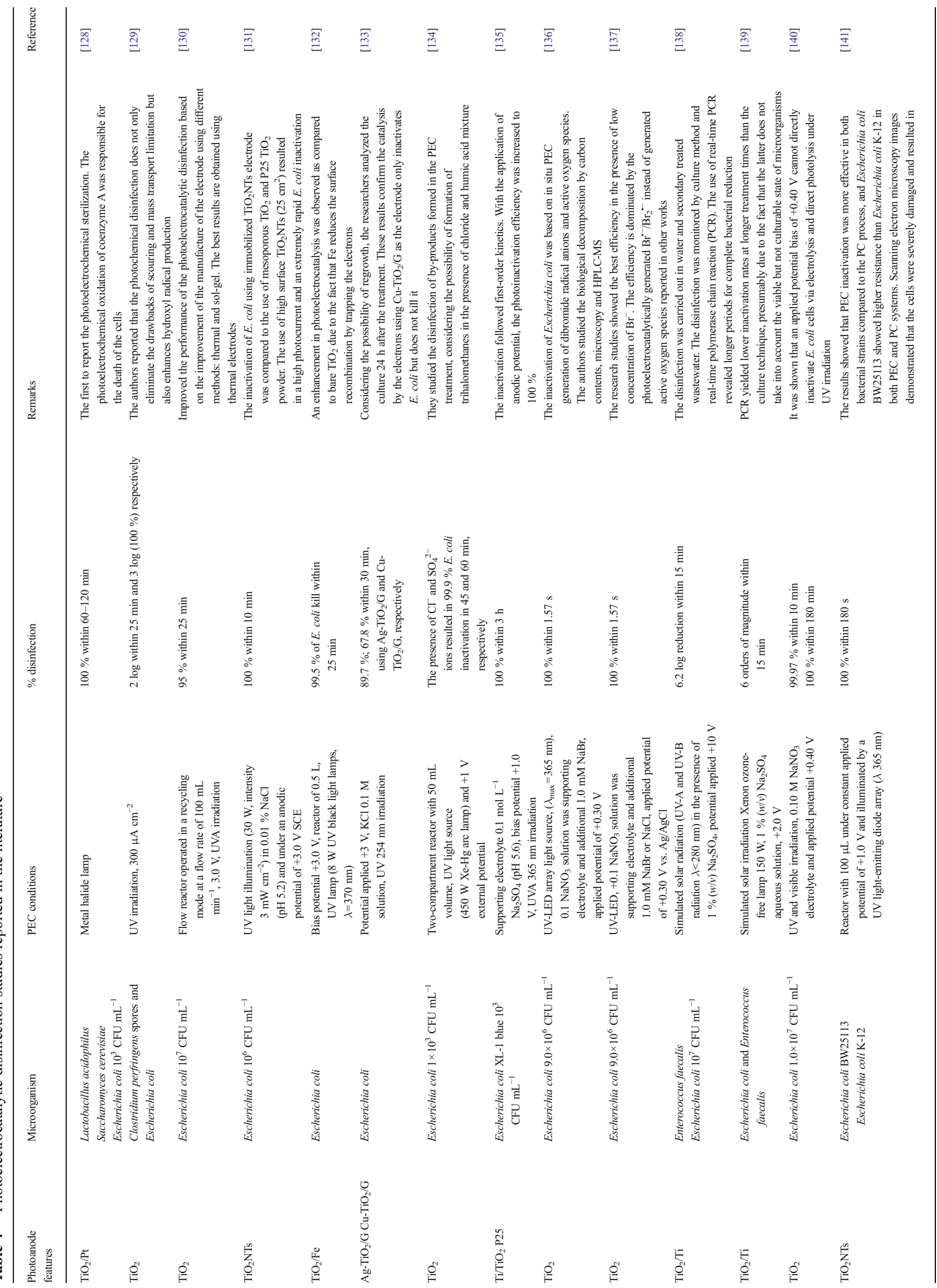




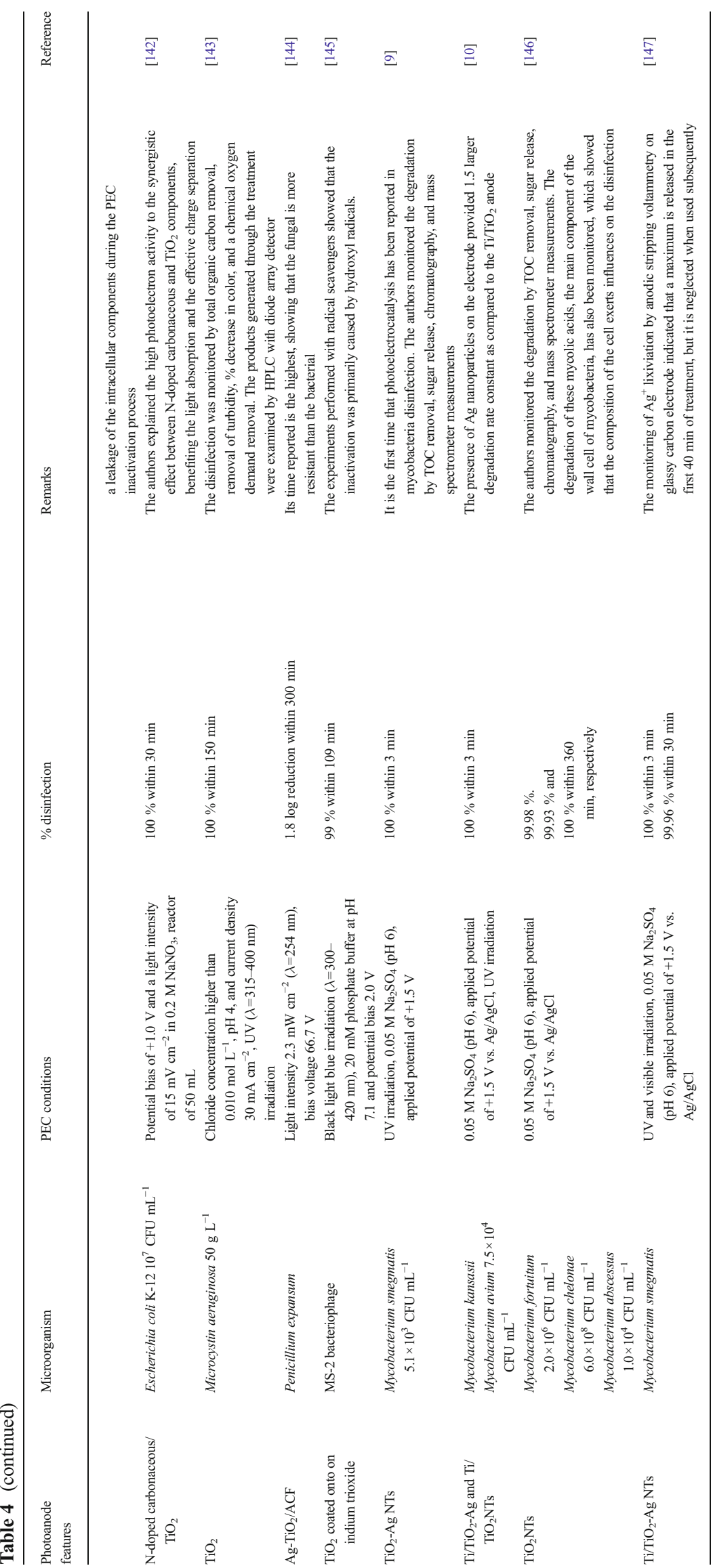


The application of $\mathrm{N}$-doped carbonaceous $/ \mathrm{TiO}_{2}$ compound has been also reported [142] for the inactivation of $E$. coli K$12\left(10^{7} \mathrm{CFU} \mathrm{mL}^{-1}\right)$. Under a constant potential bias of $+1.0 \mathrm{~V}$ and a light intensity of $15 \mathrm{mV} \mathrm{cm}^{-2}$ in $0.2 \mathrm{M} \mathrm{NaNO}_{3}, E$. coli was completely inactivated within only $30 \mathrm{~min}$ in a photoelectrocatalytic reactor of $50 \mathrm{~mL}$.

The in situ generation of chlorine radical during a photoelectrocatalytic oxidation was very efficient for the removal of microcystin toxins in surface water [143]. Chloride was oxidized on $\mathrm{TiO}_{2}$ thin film electrodes using a current density of $30 \mathrm{~mA} \mathrm{~cm}{ }^{-2}$. The treatment led to the complete removal of Microcystin aeruginosa $50 \mathrm{~g} \mathrm{~L}^{-1}$ in $0.05 \mathrm{~mol} \mathrm{~L}^{-1}$ $\mathrm{NaCl}$ after 5 min of photoelectrocatalysis.

The disinfection of the fungus Penicillium expansum has also been reported [144] using carbon felt-supported titanium dioxide $\left(\mathrm{TiO}_{2} / \mathrm{ACF}\right)$ and silver-doped $\mathrm{TiO}_{2}$-ACF under UV irradiation and bias voltage of $66.7 \mathrm{~V}$. The literature [145] has also reported the use of $\mathrm{TiO}_{2}$ particles coated onto an indium trioxide electrode for the inactivation of MS-2 bacteriophage. The experiments performed with radical scavengers showed that the inactivation was primarily caused by hydroxyl radicals generated under applied potential of $+2.0 \mathrm{~V}$ and $\mathrm{UV}$ irradiation. The authors also reported that the time required to achieve 1 log inactivation varied depending on the microorganisms and was in the order of Klebsiella pneumoniae $>$ E. coli $>$ MS-2>Staphylococcus aureus $>$ Bacillus subtilis spore $>$ Cryptosporidium parvum oocyst.

Photoelectrocatalytic oxidation has also been dedicated to the inactivation of rapid-growing mycobacteria, which are difficult to eradicate via common disinfection practices. Usually they are resistant to chlorination, glutaraldehyde, benzalkonium chloride, organomercury compounds, chlorohexidine, and even autoclavation (600 times more resistant than E. coli). Mycobacteria can occur in water distribution systems, aquariums, lakes and rivers, fish culture tank, water for hemodialysis, products and medical devices, swimming pool, and drinking water [150-152]. The complete inactivation of photoelectrocatalytic disinfection of Mycobacterium smegmatis has been reported for the first time by Brugnera et al. [9] using $\mathrm{TiO}_{2}$ nanotubular array electrodes coated with $16 \%(w / w)$ Ag nanoparticles $\left(\mathrm{Ti} / \mathrm{TiO}_{2}-\mathrm{Ag}\right.$ under applied potential of $+1.5 \mathrm{~V}$ vs. $\mathrm{Ag} / \mathrm{AgCl}$ and $\mathrm{UV}$ irradiation. The authors also monitored the degradation of cell wall by TOC removal, sugar release, chromatography, and mass spectrometer measurements. The photoelectrocatalytic oxidation promoted the inactivation in 3 min of treatment and the complete degradation of mycolic acids and polysaccharides contained in the cell wall of mycobacteria after $30 \mathrm{~min}$ of treatment. The inactivation of Mycobacterium kansasii, Mycobacterium avium, Mycobacterium fortuitum, Mycobacterium chelonae, and Mycobacterium abscessus has been also reported $[10,146,147]$ using $\mathrm{Ag}-\mathrm{TiO}_{2} \mathrm{NTs}$. For the mycobacteria concentration of $7.5 \times 10^{4} \mathrm{CFU} \mathrm{mL}^{-1}$, total inactivation was achieved after $3 \mathrm{~min}$ of treatment. The presence of $\mathrm{Ag}$ nanoparticles on the electrode provided 1.5 larger degradation rate constant as compared to the $\mathrm{Ti} / \mathrm{TiO}_{2}$ anode. The addition of $\mathrm{Ag}$ to the $\mathrm{TiO}_{2}$ nanotube electrodes can trap the photogenerated electrons, increasing the lifetime of the holes that are able to produce hydroxyl radicals. However, it was not possible to obtain $100 \%$ mineralization of the products from the bacterial lysate in the microorganism concentration used. This would be desirable because the products resulting from bacterium lysis can be used as nutrients and help induce the growth of the mycobacteria in the environment again.

It is well known in the literature [153-155] that the inactivation of microorganism by photoelectrocatalytic reaction could involve the attack of $\mathrm{OH}$ radicals and other ROS, such as ${ }^{\bullet} \mathrm{O}_{2}{ }^{-}$and $\mathrm{H}_{2} \mathrm{O}_{2}$, on the bacterial cell wall, where the bacterium and catalyst interact. Cumulative damage disrupts the cell membrane and increases cell permeability (demonstrated by potassium ion leakage), which culminates in cell lysis and death. Considering that the attack occurs on the bacterial outer wall, the differences in terms of wall structure and its cell complexity are essential $[156,157]$, since they may lead to distinct photoelectrocatalytic inactivation efficiency. Maness et al. [155] found that the ROS generated on the irradiated $\mathrm{TiO}_{2}$ surface attack the polyunsaturated phospholipids in E. coli. The lipid peroxidation reaction causes a subsequent breakdown of the cell membrane structure and therefore can be said to be associated to the mechanism underlying cell death. Sunada et al. [158] reported that endotoxin, an integral component of the outer membrane of $E$. coli, was destroyed under photocatalytic conditions when $\mathrm{TiO}_{2}$ was used. In the case of the mycobacteria [9], researchers reported that the treatments tend to destroy the peptidoglycan layer; this layer establishes covalent bonds with the mycolic acids constituting the wall structure of the mycobacteria.

Although most of the research studies available in the literature shed light and are centered on disinfection by conventional bacterial cultures, this method has considerable limitations including time-consuming incubation periods, inability for the detection of viable but not culturable (VBNC) strains, and lack of reproducibility [159]. Bacteria in this state retain their metabolic activity and pathogenic features, posing danger to public health, while they are not recoverable in standard culture media. Oxidative stress imposed by photoelectrocatalytic treatment may enhance the likelihood of VBNC state, in which bacteria retain their metabolic and pathogenic activity, though irrecoverable in standard culture media [160]. To overcome this limitation, molecular methods have been proposed, among which includes real-time PCR (quantitative, qPCR) [161-163]. From what we know in the literature [128], $96 \%(\mathrm{~m} / \mathrm{m})$ of the cell's dry weight consists of organic macromolecules, including proteins, polysaccharides, lipids, lipopolysaccharide, and nucleic acids (DNA and RNA). Therefore, determining TOC removal, polysaccharides and proteins could be an alternative way for monitoring the degradation of the organic material produced during cell lysis. 


\section{Photoelectrocatalytic Reduction}

\section{Removal of Inorganic Pollutants}

Many inorganic compounds are present in surface waters and are harmless to humans in low concentrations, but the change in these levels can be thoughtfully disturbing. According to the US Environmental Protection Agency [164], diffused sources of nutrients, including various inorganic compounds, within which include agricultural activities, are primarily responsible for accelerating the processes of eutrophication of surface water around the planet and many of such compounds can be converted into unwanted species in aquatic biota.

Among several inorganic compounds, there have been great concerns relating to the formation of bromate, which comes from the oxidation reaction via chlorination and ozonation of water containing bromide in municipal drinking water treatment $[165,166]$. The World Health Organization classifies $\mathrm{BrO}_{3}{ }^{-}$as a category I group $\mathrm{B} 2$ or "possible human" carcinogen [167].

Although the use of $\mathrm{TiO}_{2}$ as a suitable anode material to promote oxidation reaction on the irradiated working electrode has drawn the attention of several researchers, interestingly, some authors $[8,168,169]$ have indicated that irradiated $\mathrm{TiO}_{2}$ electrodes can operate in a polarization region where electrons are transferred from the n-type semiconductor to the electrolyte (cathodic current). In most n-type semiconductors, a potential barrier forms at the nonbiased semiconductor solution interface, preventing the bulk electrons from reaching the surface and reacting with electrochemical species at the expected potential [29]. However, at a potential slightly more positive than the flat band potential of the semiconductor, one might initiate the reduction of adsorbed oxygen, and at a more negative one than this potential value, the electrode behavior would become metal-like with respect to charge transfer to the electrolyte. To cite an example of such behavior, some authors have reported [8] about the reduction of $\mathrm{BrO}_{3}{ }^{-}$to $\mathrm{Br}^{-}$, occurring on the irradiated $\mathrm{Ti} / \mathrm{TiO}_{2}$ acting as photocathode. The work employing $\mathrm{TiO}_{2}$ sol-gel thin film on Ti substrate promoted $70 \%$ of the reduction of $\mathrm{BrO}_{3}{ }^{-}$to $\mathrm{Br}^{-}$at a neutral $\mathrm{pH}$ under an applied potential of $-0.20 \mathrm{~V}$ after $75 \mathrm{~min}$ of irradiation.

The observed increase of nitrate in drinking water for instance has been a recurring question in discussion forums relating to public health problems associated with environmental and agricultural activities [170, 171]. Such fact is suspected to cause serious health risks such as blue baby syndrome, hypertension, and cancer [172]. Because of this, the global legislation of several countries has been limiting nitrate ions in surface or drinking water.

The use of photoelectrocatalysis for nitrate reduction performed on $\mathrm{TiO}_{2} \mathrm{NT}$ photocathode has also been reported in the literature [173]; $100 \%$ of nitrate removal was reached after
6 min of treatment conducted in $\mathrm{NaCl} 7 \mathrm{mmol} \mathrm{L}^{-1}, \mathrm{pH} 7$, in the absence of dissolved oxygen, under UV irradiation and applied potential of $-0.2 \mathrm{~V}$ vs. $\mathrm{Ag} / \mathrm{AgCl}$. Nitrate conversion led to $7 \%$ ammonium and $93 \%$ nitrogen gaseous species generation.

Photoelectrocatalytic reduction was also carried out using p-type semiconductors with high efficiency. As demonstrated in Fig. 5, for p-type semiconductors, when subjected to external bias potential more negative than the flat band potential, electrons are enriched in the SC surface and holes are depleted. Paschoal and collaborating colleagues [7] investigated the photoelectrocatalytic reduction of nitrate on $\mathrm{Cu} / \mathrm{Cu}_{2} \mathrm{O}$ photocathodes. Under optimized conditions (applied potential of + $0.2 \mathrm{~V}, \mathrm{pH} 7$, and $\mathrm{NaCl} 0.07 \mathrm{M}$ electrolyte), $93 \%$ of nitrate is found to be removed after 75 min of treatment; $42 \%$ of the remaining nitrate and $52 \%$ of gaseous nitrogen were obtained from nitrate conversion in the cathodic compartment.

\section{Photoelectrocatalytic $\mathrm{CO}_{2}$ Reduction}

Fast-growing carbon dioxide emission and its consequences for the Earth's climate constitute an environmental threat, and there is a rapid converging agreement that $\mathrm{CO}_{2}$ emissions need to be reduced as soon as possible [101-103]. In response to this great challenge, there is a permanent search for efficient ways to prevent the accumulation of $\mathrm{CO}_{2}$, including removal, sequestration, utilization, and conversion into other compounds. Therefore, the development of methods capable of recycling $\mathrm{CO}_{2}$ into value-added products and/or through high-energy content fuel has received great attention [174, 175].

The conversion and recycling of $\mathrm{CO}_{2}$ to functional hydrocarbons has acquired notoriety since the early 1990s. A large variety of methods have been employed in the $\mathrm{CO}_{2}$ reduction since then. Some of those methods worth mentioning include biomass [175, 176], biocatalysis [177], thermochemical [178], electrochemical [174, 179, 180], and photocatalysis [11, 181, 182].

Photoelectrocatalysis technique applied to $\mathrm{CO}_{2}$ reduction has gained attention in the last years due to high conversion efficiency into high-value products [183-189]. The potential gradient applied simultaneously to the light activation of a semiconductor such as $\mathrm{GaP}, \mathrm{Si}, \mathrm{CsTe}$, and InP decorated with $\mathrm{Ag}, \mathrm{Au}, \mathrm{Cu}, \mathrm{Pb}, \mathrm{Pd}$, and $\mathrm{Ni}$; carbon nanotubes modified with $\mathrm{Pt}$ and Fe; and $\mathrm{TiO}_{2} \mathrm{NTs}$ modified with $\mathrm{Pt}, \mathrm{CuO}, \mathrm{CuO}-\mathrm{Cu}_{2} \mathrm{O}$, and $\mathrm{Cu} / \mathrm{Cu}_{2} \mathrm{O}$ has gained significant attention [183, 185, 188-194], and the main results are summarized in Table 5. $\mathrm{CO}_{2}$ reduction by the photoelectrocatalysis technique produces mainly pure or oxygenated hydrocarbons with high energetic content [202], probably involving electron transfer to their respective acceptors [188].

The first work dealing with $\mathrm{CO}_{2}$ reduction by photoelectrocatalysis was reported by Halmman in 1978 


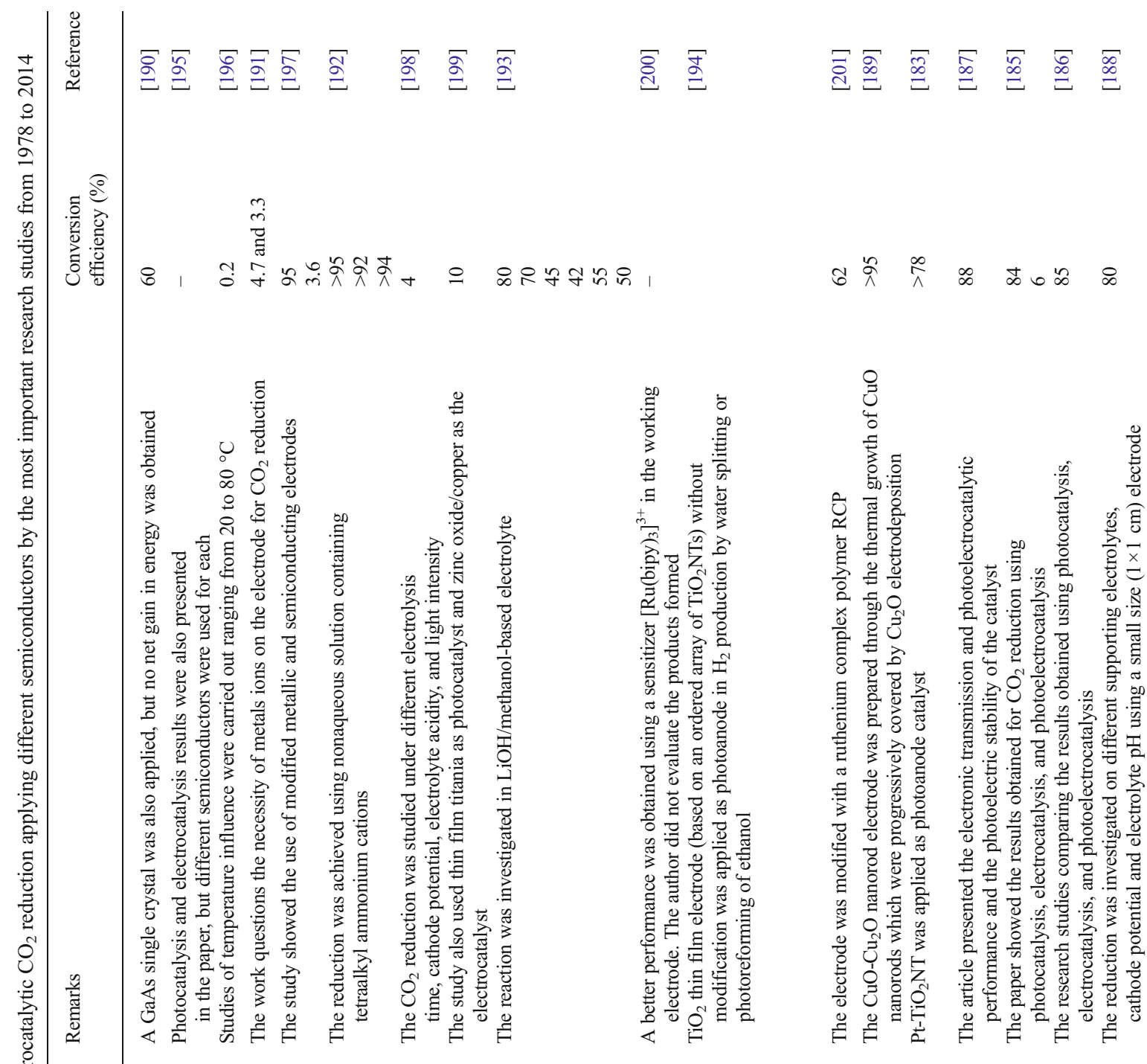

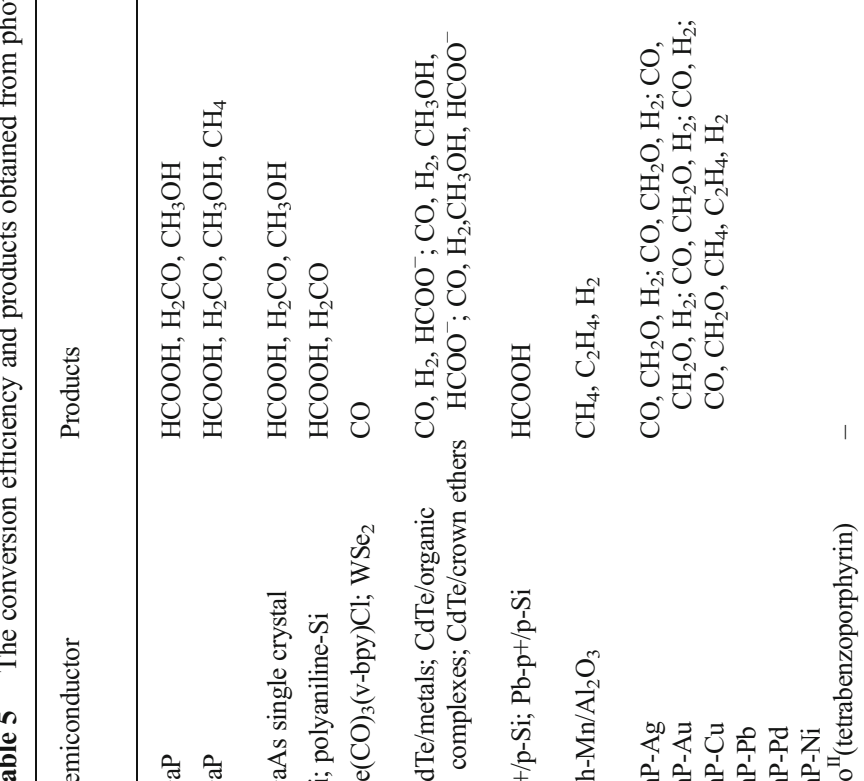

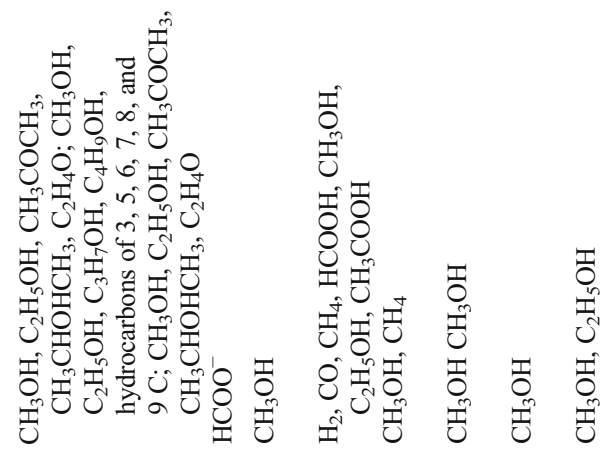

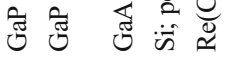

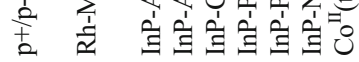
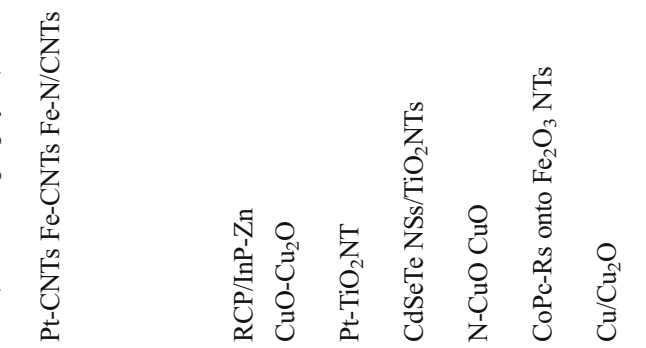
[190]. The author indicated that $\mathrm{CO}_{2}$ is converted to formic acid, methanol, and formaldehyde as products when subjected to photoelectrocatalysis on a GaP electrode. Similar products have also been obtained by other authors [183, 188, 196]. However, the process required $16 \mathrm{~h}$ of reduction to reach $60 \%$ of methanol formation.

Indeed different types of hydrogenated products with one, two, three, or more carbons can be formed under photoelectrocatalytic conditions. The product formation occurs gradually through the simultaneous or consecutive electron addition, protonation, and deprotonation of both intermediates and products $[174,203]$. The first step of this reaction is the formation of the reactive intermediate $\cdot \mathrm{CO}_{2}^{-}[189,204-206]$. The other steps are responsible for the type of products formed. The mechanism of formic acid, formaldehyde, and methanol production was presented by Brito et al. [188]. It is already known that formic acid is the first product formed; however, it is easily reduced to formaldehyde and methanol [190, 207]. Table 5 shows the main products generated and the percentage of conversion efficiency obtained from photoelectrocatalytic $\mathrm{CO}_{2}$ reduction in different semiconductors.

Table 5 confirms the huge effect of semiconductor type on the generated species during $\mathrm{CO}_{2}$ photoelectrocatalytic reduction [208]. Most of the photoelectrodes applied in the $\mathrm{CO}_{2}$ photoelectroreduction are based on p-type semiconductors $[174,183,189,190,196,198,209]$, owing to the reductive characteristic of these materials [202]. However, other factors can influence the product formation, among them including the solution $\mathrm{pH}$, temperature and the pressure of the system, $\mathrm{CO}_{2}$ concentration, applied potential, and the nature of the supporting electrolyte [203, 210, 211].

The potential influence is the easiest factor to be observed in the photoelectrocatalytic reduction of $\mathrm{CO}_{2}$ and it is closely linked to the semiconductor type [212]. The semiconductor presents catalytic activity, which is specific to each one, and this implies that each semiconductor needs a different energetic contribution, which is provided by the potential and light energy in the case of photoelectrocatalysis [41]. The applied potential in the photoelectrocatalytic $\mathrm{CO}_{2}$ reduction can influence the type of products formed, the yield of the reaction, as well as the selectivity of the system [188, 213, 214]. The yield is influenced by the potential applied in the semiconductor not only because it is inadequate for the $\mathrm{CO}_{2}$ reduction, but also by the competition it undergoes with hydrogen production occurring also at low potential $[132,136]$.

Gas solubilization is temperature dependent when considering aqueous $\mathrm{CO}_{2}$ reduction. At lower temperatures, $\mathrm{CO}_{2}$ solubility is increased in solution [193]. According to Chaplin and Wragg [210], increasing the temperature will induce a specific pathway; in this case, the reaction between $\mathrm{CO}_{2 \text { (ad) }}$ and $\mathrm{CO}_{2(\mathrm{~g})}$ resulting in $\mathrm{CO}_{(\mathrm{g})}$ and/or a formation of $\bullet \mathrm{CO}_{2}$ radical and the product obtained at the end of the conversion depend upon the nature of the supporting electrolyte.
The composition of the supporting electrolyte types has influenced $\mathrm{CO}_{2}$ reduction through photoelectrocatalysis due to a host of varying reasons. Some research studies have applied nonaqueous supporting electrolyte [181, 204] because nonaqueous solvents can dissolve more $\mathrm{CO}_{2}$ than water does [174]. Methanol-based electrolyte is one of the various nonaqueous system types applied in $\mathrm{CO}_{2}$ reduction in some research studies [174, 192, 193, 204, 215, 216]. According to Qin and collaborators [181], methanol is used as a sacrificial reagent to react with the photogenerated holes, while $\mathrm{CO}_{2}$ is reduced by photogenerated electrons. On the other hand, the use of carbonate and bicarbonate of sodium or potassium have been widely employed in the literature $[180,188,211$, 217-223] due to the maintenance of species equilibrium in the medium, besides the fact that the supporting electrolyte is not adsorbed in the semiconductor surface [202, 219, 221-223]. Other inorganic aqueous solutions such as $\mathrm{Na}_{2} \mathrm{SO}_{4}$, $\mathrm{HCl}, \mathrm{CaCl}_{2}$, and $\mathrm{VCl}_{2}$ have also been reported as supporting electrolyte option for $\mathrm{CO}_{2}$ reduction [189, 196, 224].

The $\mathrm{pH}$ of the solution is also known to exert influence on the gas solubilization, which is found to be low at very low $\mathrm{pH}$ and tends to accelerate competitive reaction of proton reduction. It thus interferes drastically in the photoelectrocatalytic reduction of $\mathrm{CO}_{2}[212,225,226]$.

Despite all the difficulties related to the conversion of carbon dioxide into products with high energetic value, the photoelectrocatalysis is a potential technique for the reduction $\mathrm{CO}_{2}$ and for the formation of different product types associated with high yield which has nowadays gained significant attention from researchers in the field.

\section{Hydrogen Generation by Photoelectrocatalysis}

The great dependence on fossil fuels aligned with their underlying intrinsic environmental problems has stimulated researchers all over the world toward the development of new renewable energy sources [227]. Among them, the use of hydrogen has attracted much attention largely due to its powerful energy carrier properties, higher energy conversion efficiency vis-à-vis conventional fossil fuels, and the generation of harmless substances during the process of combustion [227].

Taking into account the process reported in the literature regarding hydrogen production [228-230], the use of photoelectrochemical methods [231] has been described as a promising alternative for hydrogen production mainly because of the possibility of converting solar light into electricity and minimizing electron/hole recombination usually in the photocatalytic process.

In a photoelectrocatalytic process, $\mathrm{H}^{+}$reduction can occur during cathodic reactions taking place in a photoelectrocatalytic oxidation, where a semiconductor is used as photoanode, as discussed previously [13]. The reduction of $\mathrm{H}^{+}$ions is 
responsible for $\mathrm{H}_{2}$ generation through the consumption of electrons flowing through the system to the cathode. The electrolyte is responsible for the maintenance of conductivity and $\mathrm{pH}$ control.

Oddly enough though, the direct splitting of water to produce $\mathrm{H}_{2}$ and $\mathrm{O}_{2}$ by photoelectrochemical techniques has been highly pursued [92]. The first example of this reaction corresponds to the work reported by Fujishima and Honda [3]. Following the publication of this work, many research studies that ensued have been geared toward the development of new efficient and stable photoelectrode materials aiming at the generation (production) of hydrogen. Increasing efficiency and stability of photoactive materials are key challenges in order to achieve the required efficiency target of $10 \%$, which will be viable for commercialization [232]. To this end, the development of visible light active materials has been reported by a large number of researchers. As can be observed in Fig. 3, the position of valence and conduction bands will determine spontaneous water splitting in addition to the stability of the material in the PEC cell [227]. Efficient electron/hole pair separation is undoubtedly fundamental in the production process of $\mathrm{H}_{2}$, in the same way as quick electron transfer process to the counter electrode via external circuit increases PEC performance. Other features worth mentioning include visible light active materials, chemical stability, noncorrosive in electrolyte, and low cost [227].

Table 6 illustrates some photoactive materials applied as semiconductors in photoelectrocatalytic water splitting, such as $\mathrm{TiO}_{2}$ thin film, $\mathrm{TiO}_{2}$ nanotubes, $\mathrm{WO}_{3}, \mathrm{WO}_{3}$ decorated with $\mathrm{Ag}$, composites of $\mathrm{WO}_{3} / \mathrm{TiO}_{2}, \mathrm{CdS}-\mathrm{TiO}_{2}$, and $\mathrm{BiO}_{x} / \mathrm{TiO}_{2}[14$, 233-242]. The major difference between these materials reported lies in the light source used for the electrode activation and electrolyte composition. $\mathrm{BiO}_{x}-\mathrm{TiO}_{2} / \mathrm{Ti}$ has been irradiated by UV light [231] only, while $\mathrm{TiO}_{2} \mathrm{NT}$ photoactivation has been performed by $\mathrm{UV}$ and $\mathrm{TiO}_{2}$-modified electrode is activated by visible light contributions [14]. All the reported results have shown that the photoelectrochemical method could be used efficiently in hydrogen generation. Table 6 also shows the influence of morphology in photoelectrocatalytic hydrogen generation such as the use of nanoflakes, nanopores, thin films, and nanocrystalline structures of $\mathrm{WO}_{3}$ [235-238]. $\mathrm{TiO}_{2}$ has always been the most employed material, and it is noteworthy that the nanotube array morphology can be used as photoanode in $\mathrm{H}_{2}$ production without the need for any further modification or decoration $[14,233]$. $\mathrm{TiO}_{2}$ nanotubes have also been loaded with crystal and aggregates of $\mathrm{WO}_{3}$ originating from $\mathrm{WO}_{3} / \mathrm{TiO}_{2}$ compound materials $[239,240]$.

According to Table 6, carbon-modified $\mathrm{TiO}_{2}$ nanotubular arrays [234] presented higher hydrogen evolution rate of $4.4 \mathrm{~mL} \mathrm{~cm}{ }^{-2} \mathrm{~h}^{-1}$ when compared to $\mathrm{TiO}_{2}$ nanotubes of $0.4 \mathrm{~mL} \mathrm{~cm}^{-2} \mathrm{~h}^{-1}$ and $1.75 \mathrm{~mL} \mathrm{~h}^{-1}$, respectively [14, 233]. The authors attributed this to higher photoactivity, lower band gap energy, and red shift observed for the carbon-modified material. Moreover, $\mathrm{C}-\mathrm{TiO}_{2}$ is formed by a mixture of rutile and anatase phases that decreases $\mathrm{e}^{-} / \mathrm{h}^{+}$recombination and improves charge transfer. However, only $\mathrm{TiO}_{2}$ nanotubes [14] and $\mathrm{BiO}_{x}-\mathrm{TiO}_{2} / \mathrm{Ti}$ [231] photoactive materials have been described for the simultaneous organic compound degradation and hydrogen generation. The energy-time normalized $\mathrm{H}_{2}$ collection is another interesting aspect that Paulose and coworkers reported [233], expressing the direct influence of light power consumption on gas production. CdS surface modification by the addition of $\mathrm{TiO}_{2}$ affected differently the evolution of hydrogen showing the effect of morphology $\left(30.3 \mathrm{mmol} \mathrm{h}^{-1} \mathrm{~cm}^{-2}\right.$ ) [242], which is dominant when compared to simple material combination $\left(11 \mu \mathrm{mol} \mathrm{h}^{-1}\right)$ [241]. Among $\mathrm{WO}_{3}$ electrodes, thin film morphology presented the highest hydrogen generation rate of $0.13 \mathrm{mmol} \mathrm{h}^{-1}$ [236] followed by nanoflakes $\left(28 \mu \mathrm{mol} \mathrm{h} \mathrm{h}^{-1} \mathrm{~cm}^{-2}\right)$ [235] and nanoporous $\left(9.5 \mu \mathrm{mol} \mathrm{h}^{-1}\right)$ [237] structures. When nanocrystalline $\mathrm{Ag}$ is incorporated in $\mathrm{WO}_{3}$ porous films [238], hydrogen production is increased up to $3.0 \mathrm{~mL} \mathrm{~min}^{-1}$ for scaled up electrode $\left(130.56 \mathrm{~cm}^{2}\right)$ allowing $1 \mathrm{~mL}$ evolution after only $20 \mathrm{~s}$. Nevertheless, the combination of $\mathrm{WO}_{3}$ and $\mathrm{TiO}_{2}$ materials demonstrated massive enhancement on hydrogen evolution (22 and $16.2 \mathrm{~mL} \mathrm{~cm}^{-2} \mathrm{~h}^{-1}$ ) [239, 240] demonstrating how significantly charge transfer collection efficiency influences $\mathrm{H}_{2}$ production. The most expressive collection rates have been obtained for coupled $\mathrm{WO}_{3}-\mathrm{TiO}_{2}$ photoanodes proving the great effect of band gap engineering on photoelectrochemical hydrogen production.

Furthermore, some innovative aspects of water splitting have been described. Park et al. have proposed the use of stainless steel as cathode for hydrogen production in order to lower costs [231]. Seawater has been used as electrolyte by Nam and collaborators [243] in their quest to propose an alternative resource for the various water-supplying industries including hydrogen production and industrial and drinking water to help overcome water shortages worldwide. Tseng and Tseng [244] prepared a fluorine-doped tin oxide (FTO) coated with $\mathrm{TiO}_{2}$ and $\mathrm{Fe}_{2} \mathrm{O}_{3}$ photoanodes, and hydrogen efficiency has been evaluated with regard to volume production rate and solar-to-hydrogen efficiency. All the parameters have exerted some influence on $\mathrm{H}_{2}$ generation.

Geared toward large-scale application, the separation of cathodic and anodic compartments is essentially vital when it comes to the development of photoreactor geometry. Besides, in a PEC water splitting reactor, the separation of compartments can be successfully accomplished by using a proton exchange membrane (Nafion), commonly used in fuel cell, allowing $\mathrm{H}^{+}$crossover only, where $\mathrm{H}_{2}$ and $\mathrm{O}_{2}$ gases remain in each compartment [232]. Minggu and collaborators reported that the geometry and shape of the photoelectrochemical reactor directly depend on the photoelectrode assembly. Flat photoanodes allow maximum light exposure and fit the simplest photoreactor design. When only the anode material is 


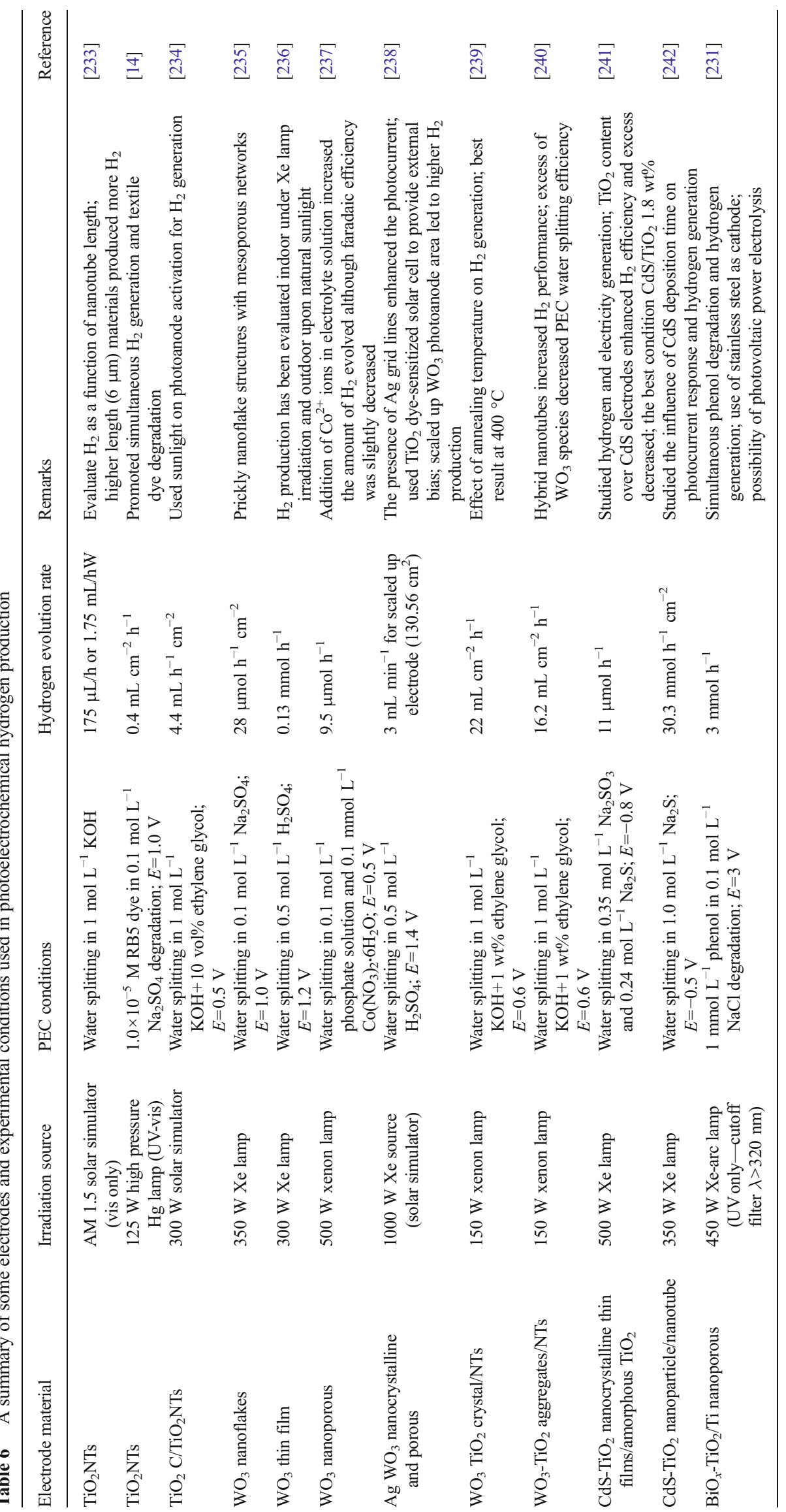


photoactive, a rectangular-shaped plate-type configuration where the anode is totally separated from the aqueous electrolyte could be used. Conversely, when both electrodes are photoactive, the anode and cathode are arranged side by side allowing light irradiation in both materials. This kind of configuration requires a photoanode and a photocathode [232].

\section{Operational Issues of the Photoelectrocatalysis Applications}

\section{Reactors}

Usually, all electrochemical advanced oxidation processes make use of similar reactors for laboratory scale. More specifically, reactors for photoelectrochemical applications must allow photoelectrode activation either externally through a quartz window or internally irradiated by artificial lamp sources, a solar simulator, or direct solar light. These electrochemical cells are commonly ascribed as photoreactors [19]. The simplest configuration is a single chamber although separate compartments for cathode and anode electrodes are quite usual; in this case, it can be made of glass or Teflon. They may also be equipped with gas separation or H-type shaped [232]. Reactor design for solar photoelectrochemical applications is reported in the literature $[245,246]$ though it should be more thoroughly described. For this purpose, there should be more interdisciplinary research contributing to advances in this field [247].

A flow plant coupled with a solar compound parabolic collector photoreactor of one-compartment filter-press Pt/airdiffusion cell was employed in dye treatment [247]. Direct solar photoelectrocatalytic treatment can be performed using a simple setup containing a large area photoelectrode, carbonPTFE air-diffusion cathode, air pump, and power supply [247]. A tubular photoreactor was also used in a PEC system for air treatment [248, 249]. In addition, Tantis and collaborators strategically placed the photoanode at the center of the photoreactor and expanded the number of lamp sources covered by a metallic reflecting cylinder in order to enhance degradation efficiency [250].

\section{Pilot Plant and Scale-Up}

Most parts of photoelectrocatalytic studies are developed in lab-scale systems. Studies concerning bench-scale or pilot plant systems for photoelectrochemical treatment are not widely reported. For comparison, conventional photocatalytic oxidation has already been carried out in scaled up reactors. For example, photoreactors like packed bed, parabolic trough, fixed/fluidized bed, inclined plate, corrugated plate, and falling film were tested [19].
Industrial effluent treatment is quite often a complex system since there is constant change in concentration and pollutant diversity. Treatment efficiency is usually based on chemical oxygen demand (COD) and/or dissolved organic carbon measurements [251].

A pilot-scale flow reactor using DSA anode and UV irradiation was employed for photoelectrocatalytic oxidation treatment of biologically pretreated sanitary landfills [252]. Membrane-based systems are sometimes coupled to industrial treatment plants in order to evaluate the economic aspects of wastewater remediation [253]. As an example, Oyama and colleagues [254] have compared several advanced oxidation processes in wastewater remediation under solar irradiation. $\mathrm{TiO}_{2}$-photoassisted ozonation in a pilot plant scale photoreactor proved to be more promising than other techniques. Oller and collaborators also reported AOPs coupled to biological treatment for scaled up systems aiming water reuse technologies. They described the use of compound parabolic collectors (CPC) collector surface for photo-Fenton oxidation in a preindustrial plant. The same kind of reactor has also been used under solar irradiation in a large-scale treatment of real effluent containing commercial pesticides [251].

Although photoelectrocatalytic degradation of contaminants in a laboratory scale is very promising, many efforts geared at applying this technique in the treatment of real effluents (such as municipal and industrial effluents) are still worthy of consideration. Few works in the literature deal with the application of decontamination photoelectrocatalysis in real effluents. Photoelectrocatalysis has been applied in the degradation of oilfield producing wastewater [130] and in textile wastewater $[46,131]$.

\section{Costs and Energy Consumption}

In order to select an effective alternative for effluent treatment, several factors should be taken into account, such as economics, regulations, condition of the effluent after treatment, operation, and robustness of the system. Among these factors, usually economics is the most important, and electric energy can represent a major fraction of the operating costs [255].

The electrochemical energy consumption $\left(E_{\mathrm{C}}\right)$ is commonly expressed in kilowatt hour per kilogram as a function of current density for effectiveness evaluation of PEC treatment. Catanho and collaborators [256] applied DSA ${ }^{\circledR}$ electrodes in a photoelectrochemical system for comparison with electrochemical oxidation. The energetic consumption for electrochemical system is much higher than photoelectrochemical treatment performed at higher current densities.

Guaraldo and coworkers also reported current efficiency for photoelectrocatalytic treatment. The estimated values were calculated from total organic carbon measurements before and after PEC treatment. At lower current density values, higher current efficiencies were obtained [48]. 
Brillas and Martínez-Huitle [247] also described current efficiency as a function of TOC and COD content. Additionally, mineralization current efficiency (MCE) is considered to express incineration of the degradation process at a given treatment time. This review highlights the relevance of energetic parameters on the feasibility of electrochemical methods. Three different equations are described for specific energy consumption considering constant current, COD, and TOC which can be expressed in kilowatt hour per cubic meter, kilowatt hour per gram COD, and kilowatt hour per gram TOC, respectively. For pilot-scale applications, lower specific energy consumption and high MCE are preferred.

Different models for calculating photoelectrocatalytic cell efficiency were proposed in Lianos' review [13]. Some factors should be considered when calculating PEC efficiency such as exciting radiation energy, effective output energy, chemical energy, and input energy by applied potential. For this reason, it is usually complicated to consider some of these factors and finally applying the related models. The efficiency can be expressed by incident photon to current conversion efficiency (IPCE), external quantum efficiency (EQE), and internal quantum efficiency (IQE). IPCE and EQE consider the number of charge carriers over the number of incident photon ratio on the cell, while IQE takes into consideration the ratio of the number of charge carriers over the actual number of photons absorbed by the cell. Both models can be used to express efficiency of PEC cells.

Most advanced oxidation processes, including photoelectrocatalytic oxidation, are electric energy intensive, since electric energy can represent a major fraction of the operating costs. Bolton et al. [255] proposed a simple figures-of-merit based on electric energy consumption. Using these figures-of-merit, it is possible to compare the energy consumption (or solar energy efficiency) of any advanced oxidation technology, independent of the nature of the system. The proposed equations depend on the kinetic order regime:

i. Electric energy per mass, $E_{\mathrm{EM}}(\mathrm{kWh} / \mathrm{kg})$, for high contaminant concentrations, phenomenological zero-order in $C$

$$
E_{\mathrm{EM}}=\frac{P t 10^{6}}{V\left(\gamma_{\mathrm{i}}-\gamma_{\mathrm{f}}\right)}
$$

ii. Electric energy per order, $E_{\mathrm{EO}}\left(\mathrm{kWh} / \mathrm{m}^{3} /\right.$ order $)$, is the electric energy in kilowatt hours $[\mathrm{kWh}]$ required to degrade a contaminant $C$ by one order of magnitude in a unit volume of contaminated water or air (overall first order in $C$ )

$$
E_{\mathrm{EO}}=\frac{P t 1000}{V \lg \left(c_{\mathrm{i}}-c_{\mathrm{f}}\right)}
$$

where $P$ is the rated power $(\mathrm{kW})$ of the system, $V$ is the treated volume (L) of water or air treated in time $t(\mathrm{~h}), \gamma_{\mathrm{i}}$ and $\gamma_{\mathrm{f}}$ are the initial and final mass concentrations $\left(\mathrm{mg} \mathrm{L}^{-1}\right)$, and $c_{\mathrm{i}}$ and $c_{\mathrm{f}}$ are the initial and final concentrations $\left(\mathrm{mol} \mathrm{L}^{-1}\right)$, respectively. These figures-of-merit are more suitable to express the energy consumption because usually the estimated energy costs are expressed per unit volume or mass for a particular waste; however, such notation does not take into account the concentration of the contaminant nor the treatment goals.

As stated before, photoelectrode materials are being activated by solar light in order to lower costs. Besides, several application types are reported aiming reduction of expenses by better use of radiation. Ideally, the use of photovoltaic materials coupled to photoelectrochemical systems has been described for lab scale. This system considers solar light absorption to power the photocatalytic system decreasing power supply dependence and consequently maintenance cost. Bolton and collaborators also described figures-of-merit for solardriven systems to provide a direct link to solar energy efficiency of different AOPs [255].

Ordinarily, pollutant degradation pathways and premodeling processes are useful information for real effluent treatment from an economical to a practical point of view for general electrochemical advanced oxidation processes. For this reason, a solar-mediated process is an attractive strategy for cost reduction as well as affordable electrical power source. A combination of an advanced oxidation process like photoelectrocatalysis to other remediation technologies could be an interesting economical aspect for achieving efficient industrial decontamination [251,257-260].

\section{Final Considerations}

Considerable improvements in the efficiency of photoelectrocatalytic systems have been made since its inception. This was possible largely due to the great advances in the materials, mainly the contribution of nanostructured semiconductors and modified materials which enable the absorption of visible light (solar irradiation).

In contrast, many studies applying photoelectrocatalysis in water treatment have been carried out by monitoring the concentration of the target compound without devoting their attention to the possible products generated after the partial degradation. By virtue of that, the core goal to be pursued ought to be the total mineralization of the pollutants. In that light, the evaluation of genotoxic, cytotoxic, and mutagenic responses stand to be relevant owing to the fact that some derivatives or metabolites formed during photoelectrocatalytic treatment can be more dangerous compared to the initial contaminant.

The main disadvantage of photoelectrocatalytic treatment lies in efficiency losses in highly concentrated matrices (mainly highly colored media) due to light absorption by the medium resulting in the reduction of photoanode activation. Thus, although it is a powerful technique for treatment, sometimes it is necessary to align it with other techniques such as physical 
treatments (to remove matter particles), biological treatment, or other advance oxidation processes. Finally, it is worth pointing out the relevant nature of the development of efficient reactors capable of working on a scale-up level of industrial plant treatment.

Furthermore, photoelectrocatalytic oxidation has shown to be a powerful technique for water disinfection. Photoelectrocatalysis promotes faster inactivation of several microorganisms at a short required time of treatment. In addition, the hydroxyl radicals are also found to destroy products lixiviated from the cell lyse, promoting high mineralization of the organic materials released during treatment and wall cell destruction. The different groups of microorganisms vary in their susceptibility to the treatment, but PEC seems to be an excellent alternative providing greater efficiency for the disinfection of water contaminated by $E$. coli, mycobacteria, and fungus.

Photoelectrocatalysis has shown to be appropriate for inorganic anion reduction. An overview of photoelectrocatalytic $\mathrm{CO}_{2}$ reduction has also shown that the method can also be used to generate products with high added value, including methanol, formic acid, formaldehyde, acetaldehyde, and acetone. The preliminary studies indicate that the subject deserves attention as it could lead to the development of an effective and economical method for the conversion of $\mathrm{CO}_{2}$ in valueadded products.

On the other hand, the development of new, effective, and stable visible light active materials is the key to efficient photoelectrochemical hydrogen production. Development of new and simpler hydrogen analysis methods could contribute enormously to the progress on this field. The possibility of simultaneous wastewater treatment and hydrogen production contributes toward the exploitation of photoelectrocatalysis versatility. The technique potential on hydrogen production using solar light irradiation is a promising feature capable of bringing meaningful contribution to our societies in both economic and environmental spheres.

\section{References}

1. S. Kato, F. Mashio, Abtr. B. Annu. Meet Chem. Soc. Jpn. 223 (1956)

2. K. Hashimoto, H. Irie, A. Fujishima, Jpn. J. Appl. Phys. Part 144 , 8269 (2005)

3. A. Fujishima, K. Honda, 238, 37 (1972)

4. G.G. Bessegato, J.C. Cardoso, M.V.B. Zanoni, Catal. Today 240, 100 (2014)

5. J.C. Cardoso, T.M. Lizier, M.V.B. Zanoni, Appl. Catal B 99, 96 (2010)

6. M.F. Brugnera, K. Rajeshwar, J.C. Cardoso, M.V.B. Zanoni, Chemosphere 78, 569 (2010)

7. F.M.M. Paschoal, L. Nuñez, M.R. de Vasconcelos Lanza, M.V.B. Zanoni, J. Adv. Oxid. Technol 16, 63 (2013)
8. F.M.M. Paschoal, G. Pepping, M.V.B. Zanoni, M. Anderson, Environ Sci Technol 43, 7496 (2009)

9. M.F. Brugnera, M. Miyata, G.J. Zocolo, C.Q.F. Leite, M.V.B. Zanoni, Electrochim Acta 85, 33 (2012)

10. M.F. Brugnera, M. Miyata, G.J. Zocolo, C.Q.F. Leite, M.V.B. Zanoni, Water Res 47, 6596 (2013)

11. M. Tahir, N.S. Amin, Energy Convers Manage 76, 194 (2013)

12. T.J. LaTempa, S. Rani, N. Bao, C.A. Grimes, Nanoscale 4, 2245 (2012)

13. P. Lianos, J Hazard Mater 185, 575 (2011)

14. M.V.B. Zanoni, T.T. Guaraldo, ECS Trans 50, 63 (2013)

15. S. Kakuta, T. Abe, ACS Appl Mater Interfaces 1, 2707 (2009)

16. R. Abe, J Photochem Photobiol, C 11, 179 (2010)

17. H. Zhang, G. Chen, D.W. Bahnemann, J Mater Chem 19, 5089 (2009)

18. I. Paramasivam, H. Jha, N. Liu, P. Schmuki, Small 8, 3073 (2012)

19. R. Daghrir, P. Drogui, D. Robert, J Photochem Photobiol, A 238, $41(2012)$

20. T.A. Egerton, J Chem Technol Biotechnol 86, 1024 (2011)

21. K. Rajeshwar, in Encyclopedia of Electrochemistry, ed. by A. J. Bard, M. Stratmann, S. Licht (Wiley-VCH, Weinhein, 2007), p. 608.

22. A.L. Linsebigler, G.Q. Lu, J.T. Yates, Chem Rev 95, 735 (1995)

23. K. Rajeshwar, M.E. Osugi, W. Chanmanee, C.R. Chenthamarakshan, M.V.B. Zanoni, P. Kajitvichyanukul, R. Krishnan-Ayer, J Photochem Photobiol C 9, 171 (2008)

24. M. Pelaez, N.T. Nolan, S.C. Pillai, M.K. Seery, P. Falaras, A.G. Kontos, P.S.M.M. Dunlop, J.W.J.J. Hamilton, J.A.A. Byrne, K. O'Shea, M.H. Entezari, D.D. Dionysiou, K.O. Shea, M.H. Entezari, D.D. Dionysiou, Appl Catal. B 125, 331 (2012)

25. G. G. Bessegato, T. T. Guaraldo, M. V. B. Zanoni, in Modern Electrochemical Methods in Nano, Surface and Corrosion Science, ed. by M. Aliofkhazraei (InTech, Rijeka, 2014), pp. 271-319.

26. K. Vinodgopal, S. Hotchandani, P. V Kamat. J Phys Chem 97, 9040 (1993)

27. J. Georgieva, E. Valova, S. Armyanov, N. Philippidis, I. Poulios, S. Sotiropoulos, J Hazard Mater 211, 30 (2012)

28. K. Rajeshwar, J Appl Electrochem 25, 1067 (1995)

29. H.O. Finklea, Semiconductor Electrodes (Elsevier, New York, 1988)

30. M. Palaniappan, P.H. Gleick, L. Allen, M.J. Cohen, J. ChristianSmith, C. Smith, Clearing the Waters: a Focus on Water Quality Solutions (United Nations Environment Programme, Nairobi, 2010)

31. A.C. Gore, D. Crews, L.L. Doan, M. La Merrill, H. Patisaul, A. Zota, Introduction to Endocrine Disrupting Chemicals (EDCs): a Guide for Public Interest Organizations and Policy-Makers (Endocrine Society), 2014

32. D.H. Kim, M. Anderson, Environ Sci Technol 28, 479 (1994)

33. I.U. Haque, J.F. Rusling, Chemosphere 26, 1301 (1993)

34. S. Ichikawa, R. Doi, Catal. Today 27, 271 (1996)

35. P. Roy, S. Berger, P. Schmuki, Angew Chem Int Ed 50, 2904 (2011)

36. K. Vinodgopal, P.V. Kamat, Sol Energy Mater Sol Cells 38, 401 (1995)

37. H. Hidaka, T. Shimura, K. Ajisaka, S. Horikoshi, J. Zhao, N. Serpone, J. Photochem. Photobiol., A 109, 165 (1997)

38. J. Rodríguez, M. Gómez, S.-E. Lindquist, C.G. Granqvist, Thin Solid Films 360, 250 (2000)

39. X.Z. Li, H.L. Liu, P.T. Yue, Y.P. Sun, Environ Sci Technol 34, $4401(2000)$

40. X.Z. Li, F.B. Li, C.M. Fan, Y.P. Sun, Water Res 36, 2215 (2002)

41. M.V.B. Zanoni, J.J. Sene, M. Anderson, J Photochem Photobiol. A 157, 55 (2003) 
42. M.E. Osugi, G.A. Umbuzeiro, M. Anderson, M.V.B. Zanoni, Electrochim Acta 50, 5261 (2005)

43. X. Quan, X. Ruan, H. Zhao, S. Chen, Y. Zhao, Environ Pollut 147, 409 (2007)

44. N. Philippidis, S. Sotiropoulos, A. Efstathiou, I. Poulios, J Photochem Photobiol. A 204, 129 (2009)

45. G. Palmisano, V. Loddo, H.H. El Nazer, S. Yurdakal, V. Augugliaro, R. Ciriminna, M. Pagliaro, Chem Eng J 155, 339 (2009)

46. F.M.M. Paschoal, M. Anderson, M.V.B. Zanoni, J Hazard Mater 166, 531 (2009)

47. F.M.M. Paschoal, M. Anderson, M.V.B. Zanoni, Desalination 249, 1350 (2009)

48. T.T. Guaraldo, S.H. Pulcinelli, M.V.B. Zanoni, J Photochem Photobiol. A 217, 259 (2011)

49. V.M. Daskalaki, I. Fulgione, Z. Frontistis, L. Rizzo, D. Mantzavinos, Catal. Today 209, 74 (2013)

50. X. Zhao, L. Guo, C. Hu, H. Liu, J. Qu, Appl Catal. B 144, 478 (2014)

51. Y. Liu, X. Gan, B. Zhou, B. Xiong, J. Li, C. Dong, J. Bai, W. Cai, J Hazard Mater 171, 678 (2009)

52. J.C. Cardoso, M.V. Boldrin Zanoni, Sep Sci Technol 45, 1628 (2010)

53. Z. Miao, D.S. Xu, J.H. Ouyang, G.L. Guo, X.S. Zhao, Y.Q. Tang, Nano Lett 2, 717 (2002)

54. K. Shankar, J.I. Basham, N.K. Allam, O.K. Varghese, G.K. Mor, X. Feng, M. Paulose, J.A. Seabold, K.-S. Choi, C.A. Grimes, J Phys Chem C 113, 6327 (2009)

55. J.J. Wu, C.C. Yu, J Phys Chem B 108, 3377 (2004)

56. Y. Li, H. Yu, C. Zhang, L. Fu, G. Li, Z. Shao, B. Yi, Int J Hydrogen Energy 38, 13023 (2013)

57. F. Wang, Z. Zheng, F. Jia, Mater Lett 71, 141 (2012)

58. C.A. Grimes, G.K. Mor, TiO2 Nanotube Arrays: Synthesis, Properties, Applications (Springer, New York, 2009)

59. G.K. Mor, O.K. Varghese, M. Paulose, K. Shankar, C.A. Grimes, Sol Energy Mater Sol Cells 90, 2011 (2006)

60. H.-H. Ou, S.-L. Lo, Sep Purif Technol 58, 179 (2007)

61. M. Zhang, Y. Bando, K. Wada, J Mater Sci Lett 20, 167 (2001)

62. D.V. Bavykin, J.M. Friedrich, F.C. Walsh, Adv Mater 18, 2807 (2006)

63. Y.-C. Nah, I. Paramasivam, P. Schmuki, Chemphyschem 11, 2698 (2010)

64. J.M. Macak, H. Tsuchiya, A. Ghicov, K. Yasuda, R. Hahn, S. Bauer, P. Schmuki, Curr Opin Solid State Mater Sci 11, 3 (2007)

65. L.C. Almeida, M.V.B. Zanoni, J Braz Chem Soc 25, 579 (2014)

66. Q. Zhang, Y. Jing, A. Shiue, C.-T. Chang, T. Ouyang, C.-F. Lin, Y.-M. Chang, J. Environ. Sci. Heal. Part B-Pesticides Food Contam. Agric Wastes 48, 686 (2013)

67. E. Sennik, Z. Colak, N. Kilinc, Z.Z. Ozturk, Int J Hydrogen Energy 35, 4420 (2010)

68. R. Zhao, M. Xu, J. Wang, G. Chen, Electrochim Acta 55, 5647 (2010)

69. K.-S. Mun, S.D. Alvarez, W.-Y. Choi, M.J. Sailor, ACS Nano 4, 2070 (2010)

70. G.K. Mor, K. Shankar, M. Paulose, O.K. Varghese, C.A. Grimes, Nano Lett 6, 215 (2006)

71. C.E. Patrick, F. Giustino, Adv Funct Mater 21, 4663 (2011)

72. M. Ni, M.K.H. Leung, D.Y.C. Leung, K. Sumathy, Renew Sustain Energy Rev 11, 401 (2007)

73. H. Wu, Z. Zhang, J Solid State Chem 184, 3202 (2011)

74. J.H. Park, S. Kim, A.J. Bard, Nano Lett 6, 24 (2006)

75. Q. Zhang, E. Ackerman, Y. Li, Abstr. Pap. Am. Chem. Soc. 241, (2011)

76. K.C. Popat, L. Leoni, C.A. Grimes, T.A. Desai, Biomaterials 28 , 3188 (2007)
77. K.C. Popat, M. Eltgroth, T.J. La Tempa, C.A. Grimes, T.A. Desai, Small 3, 1878 (2007)

78. Y. Xie, Electrochim Acta 51, 3399 (2006)

79. J.L. Esbenshade, J.C. Cardoso, M.V. Boldrin Zanoni, J Photochem Photobiol A 214, 257 (2010)

80. Y. Xin, H. Liu, L. Han, Y. Zhou, J Hazard Mater 192, 1812 (2011)

81. Q. Zhang, J. Zhu, Y. Wang, J. Feng, W. Yan, H. Xu, Appl Surf Sci 308, 161 (2014)

82. R. Daghrir, P. Drogui, I. Ka, M.A. El Khakani, J Hazard Mater 199-200, 15 (2012)

83. R. Daghrir, P. Drogui, A. Dimboukou-Mpira, M.A. El Khakani, Chemosphere 93, 2756 (2013)

84. R. Daghrir, P. Drogui, M.A. El Khakani, Electrochim Acta 87, 18 (2013)

85. R. Li, S.E. Williams, Q. Li, J. Zhang, C. Yang, A. Zhou, Electrocatalysis 5, 379 (2014)

86. H. Liu, X. Cao, G. Liu, Y. Wang, N. Zhang, T. Li, R. Tough, Chemosphere 93, 160 (2013)

87. H. Wang, X. Zhang, Y. Su, H. Yu, S. Chen, X. Quan, F. Yang, Appl Surf Sci 311, 851 (2014)

88. Z. Liu, X. Zhang, S. Nishimoto, M. Jin, D.A. Tryk, T. Murakami, A. Fujishima, J Phys Chem C 112, 253 (2008)

89. N. Serpone, J Phys Chem B 110, 24287 (2006)

90. R. Daghrir, P. Drogui, N. Delegan, M.A. El Khakani, Sci Total Environ 466-467, 300 (2014)

91. J. Li, N. Lu, X. Quan, S. Chen, H. Zhao, Ind Eng Chem Res 47, 3804 (2008)

92. J. Gong, W. Pu, C. Yang, J. Zhang, Catal Commun 36, 89 (2013)

93. K. Yang, W. Pu, Y. Tan, M. Zhang, C. Yang, J. Zhang, Mater Sci Semicond Process 27, 777 (2014)

94. H. Liu, G. Liu, X. Shi, Colloids Surf A Physicochem Eng Asp 363, 35 (2010)

95. Z. Zhang, Y. Yuan, L. Liang, Y. Cheng, G. Shi, L. Jin, J Hazard Mater 158, 517 (2008)

96. X. Cheng, G. Pan, X. Yu, T. Zheng, Electrochim Acta 105, 535 (2013)

97. Y. Zhu, R. Wang, W. Zhang, H. Ge, L. Li, Appl Surf Sci 315, 149 (2014)

98. G.G. Bessegato, J.C. Cardoso, B.F. Silva, M.V.B. Zanoni, J Photochem Photobiol A 276, 96 (2013)

99. T. Li, X. Li, Q. Zhao, Y. Shi, W. Teng, Appl Catal B 156-157, 362 (2014)

100. Q. Chen, H. Liu, Y. Xin, X. Cheng, Chem Eng J 241, 145 (2014)

101. X. Cheng, H. Liu, Q. Chen, J. Li, P. Wang, J Hazard Mater 254255, 141 (2013)

102. N. Lu, S. Chen, H. Wang, X. Quan, H. Zhao, J Solid State Chem 181, 2852 (2008)

103. H. Liu, G. Liu, J. Fan, Q. Zhou, H. Zhou, N. Zhang, Z. Hou, M. Zhang, Z. He, Chemosphere 82, 43 (2011)

104. W. Tang, X. Chen, J. Xia, J. Gong, X. Zeng, Mater Sci Eng B 187, 39 (2014)

105. T.T. Guaraldo, T.B. Zanoni, S.I.C. de Torresi, V.R. Gonçales, G.J. Zocolo, D.P. Oliveira, M.V.B. Zanoni, Chemosphere 91, 586 (2013)

106. J. Georgieva, S. Armyanov, E. Valova, I. Poulios, S. Sotiropoulos, Electrochem Commun 9, 365 (2007)

107. J. Georgieva, S. Armyanov, E. Valova, N. Philippidis, I. Poulios, S. Sotiropoulos, J Adv Oxid Technol 11, 300 (2008)

108. J. Georgieva, S. Sotiropoulos, S. Armyanov, N. Philippidis, I. Poulios, J Appl Electrochem 41, 173 (2010)

109. Y. Xin, M. Gao, Y. Wang, D. Ma, Chem Eng J 242, 162 (2014)

110. M. Zhang, C. Yang, W. Pu, Y. Tan, K. Yang, J. Zhang, Electrochim Acta 148, 180 (2014)

111. X. Wang, H. Zhao, X. Quan, Y. Zhao, S. Chen, J Hazard Mater 166, 547 (2009) 
112. G. Qin, Q. Wu, Z. Sun, Y. Wang, J. Luo, S. Xue, J Hazard Mater 199-200, 226 (2012)

113. W. Liao, J. Yang, H. Zhou, M. Murugananthan, Y. Zhang, Electrochim Acta 136, 310 (2014)

114. L.-C. Chen, Y.-C. Ho, W.-S. Guo, C.-M. Huang, T.-C. Pan, Electrochim Acta 54, 3884 (2009)

115. L.C. Almeida, S. Garcia-Segura, N. Bocchi, E. Brillas, Appl Catal B 103, 21 (2011)

116. W.H. Leng, W.C. Zhu, J. Ni, Z. Zhang, J.Q. Zhang, C.N. Cao, Appl Catal A 300, 24 (2006)

117. M. Kaneko, J. Nemoto, H. Ueno, N. Gokan, K. Ohnuki, M. Horikawa, R. Saito, T. Shibata, Electrochem Commun 8, 336 (2006)

118. H. Ueno, J. Nemoto, K. Ohnuki, M. Horikawa, M. Hoshino, M. Kaneko, J Appl Electrochem 39, 1897 (2009)

119. M. Kaneko, H. Ueno, R. Saito, J. Nemoto, Catal Lett 131, 184 (2009)

120. M. Antoniadou, P. Lianos, Catal Today 144, 166 (2009)

121. M. Pagliaro, R. Ciriminna, H. Kimura, M. Rossi, C. Della Pina, Angew Chem Int Ed 46, 4434 (2007)

122. M. Antoniadou, D.I. Kondarides, P. Lianos, Catal Lett 129, 344 (2009)

123. P. Panagiotopoulou, M. Antoniadou, D.I. Kondarides, P. Lianos, Appl Catal B 100, 124 (2010)

124. O.K. Varghese, C.A. Grimes, Sol Energy Mater Sol Cells 92, 374 (2008)

125. A. Patsoura, D. I. Kondarides, X. E. Verykios, Appl Catal B 64, 171 (2006)

126. S. Malato, P. Fernández-Ibáñez, M.I. Maldonado, J. Blanco, W. Gernjak, Catal Today 147, 1 (2009)

127. O.K. Dalrymple, E. Stefanakos, M.A. Trotz, D.Y. Goswami, Appl Catal B 98, 27 (2010)

128. T. Matsunaga, R. Tomoda, T. Nakajima, H. Wake, FEMS Microbiol Lett 29, 211 (1985)

129. I.M. Butterfield, P.A. Christensen, T.P. Curtis, J. Gunlazuardi, Water Res 31, 675 (1997)

130. P.A. Christensen, T.P. Curtis, T.A. Egerton, S.A.M. Kosa, J.R. Tinlin, Appl Catal B 41, 371 (2003)

131. N. Baram, D. Starosvetsky, J. Starosvetsky, M. Epshtein, R. Armon, Y. Ein-Eli, Electrochim Acta 54, 3381 (2009)

132. T.A. Egerton, S.A.M. Kosa, P.A. Christensen, Phys Chem Chem Phys 8, 398 (2006)

133. F. Rahmawati, T. Kusumaningsih, A.M. Hapsari, A. Hastuti, Chem Pap 64, 557 (2010)

134. H. Selcuk, Water Res 44, 3966 (2010)

135. N. Philippidis, E. Nikolakaki, S. Sotiropoulos, I. Poulios, J Chem Technol Biotechnol 85, 1054 (2010)

136. A. Li, X. Zhao, H. Liu, J. Qu, Water Res 45, 6131 (2011)

137. G. Li, X. Liu, H. Zhang, P.-K. Wong, T. An, H. Zhao, Appl Catal B 140-141, 225 (2013)

138. D. Venieri, E. Chatzisymeon, S.S. Sofianos, E. Politi, N.P. Xekoukoulotakis, A. Katsaounis, D. Mantzavinos, Environ Sci Pollut Res Int 19, 3782 (2012)

139. D. Venieri, E. Chatzisymeon, E. Politi, S.S. Sofianos, A. Katsaounis, D. Mantzavinos, J Water Health 11, 21 (2013)

140. X. Liu, H. Zhang, C. Liu, J. Chen, G. Li, T. An, P.-K. Wong, H. Zhao, Catal Today 224, 77 (2014)

141. X. Nie, G. Li, M. Gao, H. Sun, X. Liu, H. Zhao, P.-K. Wong, T. An, Appl Catal B 147, 562 (2014)

142. X. Nie, G. Li, P.-K. Wong, H. Zhao, T. An, Catal Today 230, 67 (2014)

143. L.E. Fraga, M. Anderson, M.L.P.M.A. Beatriz, F.M.M. Paschoal, L.P. Romao, M.V.B. Zanoni, Electrochim Acta 54, 2069 (2009)

144. S.-Y. Ye, M.-L. Fan, X.-L. Song, S.-C. Luo, Int J Food Microbiol 136, 332 (2010)

145. M. Cho, E.L. Cates, J.-H. Kim, Water Res 45, 2104 (2011)
146. M. F. Brugnera, M. Miyata, G. J. Zocolo, C. Q. F. Leite, M. V. B. Zanoni, J. Chem. Technol. Biotechnol. n/a (2013)

147. M.F. Brugnera, M. Miyata, C.Q. Fujimura Leite, M.V.B. Zanoni, J Photochem Photobiol A 278, 1 (2014)

148. M.V.B. Zanoni, J.J. Sene, H. Selcuk, M. Anderson, Environ Sci Technol 38, 3203 (2004)

149. G. Li, X. Liu, H. Zhang, T. An, S. Zhang, A.R. Carroll, H. Zhao, J Catal 277, 88 (2011)

150. A.B... Kressel, F. Kidd, Infect Control Hosp Epidemiol 22, 414 (2001)

151. M.J. Nieuwenhuijsen, M.B. Toledano, N.E. Eaton, J. Fawell, P. Elliott, Occup Environ Med 57, 73 (2000)

152. E.-S. Lee, T.-H. Yoon, M.-Y. Lee, S.-H. Han, J.-O. Ka, Water Res 44, $1329(2010)$

153. M. R. Hoffmann, S. T. Martin, W. Choi, D. W. Bahnemannt, Chem. Rev. 69 (1995)

154. A. Mills, S. Le Hunte, J Photochem Photobiol A 108, 1 (1997)

155. P.C. Maness, S. Smolinski, D.M. Blake, Z. Huang, E.J. Wolfrum, W.A. Jacoby, Appl Environ Microbiol 65, 4094 (1999)

156. R. van Grieken, J. Marugán, C. Pablos, L. Furones, A. López, Appl Catal B 100, 212 (2010)

157. M.J. Figueras, J.J. Borrego, Int J Environ Res Public Health 7, 4179 (2010)

158. K. Sunada, Y. Kikuchi, K. Hashimoto, A. Fujishima, Environ Sci Technol 32, 726 (1998)

159. M.M. Lleo, B. Bonato, M.C. Tafi, C. Signoretto, C. Pruzzo, P. Canepari, Lett Appl Microbiol 40, 289 (2005)

160. A. Muela, C. Seco, E. Camafeita, I. Arana, M. Orruño, J.A. López, I. Barcina, FEMS Microbiol Ecol 64, 28 (2008)

161. I. Brettar, M.G. Höfle, Curr Opin Biotechnol 19, 274 (2008)

162. E. Frahm, U. Obst, J Microbiol Methods 52, 123 (2003)

163. N. Wéry, C. Lhoutellier, F. Ducray, J.-P. Delgenès, J.-J. Godon, Water Res 42, 53 (2008)

164. United States Environmental Protection Agency, Disinfectants and Disinfection Byproducts (Stage $1 \&$ Stage 2 DBPR) (USEPA, 2010) http://www.epa.gov/ogwdw/mdbp/qrg_st1.pdf. Accessed 12 Dec 2014

165. H.S. Weinberg, C.A. Delcomyn, V. Unnam, Environ Sci Technol 37, 3104 (2003)

166. R.D. Letterman, Water Quality, Treatment: a Handbook of Community Water Supplies, Fifthth edn. (McGraw-Hill, New York, 1999)

167. J.K. Fawell, J.R. Hickman, U. Lurid, B. Mintz, E.B. Pike, Guidelines for Drinking-Water Quality, Secondth edn. (World Health Organization, Geneva, 1996)

168. Y. Matsumoto, J. Kurimoto, T. Shimizu, E. Sato, J Electrochem Soc 128, 1040 (1981)

169. J.F. Julião, F. Decker, R. Brenzikofer, M. Abramovich, J Electrochem Soc 127, 2067 (1980)

170. A.A. Avery, Environ Health Perspect 107, 583 (1999)

171. M.M. Higarashi, A. Kunz, R.M. Mattei, Quim Nova 31, 1156 (2008)

172. J.I. Waddington (ed.), Health Hazards from Nitrates in DrinkingWater (World Health Organization, Copenhagen, 1984)

173. F.A. Sayão, L. Nuñez, M.V.B. Zanoni, J Braz Chem Soc 25, 1153 (2014)

174. S. Ohya, S. Kaneco, H. Katsumata, T. Suzuki, K. Ohta, Catal Today 148, 329 (2009)

175. K. Gao, K.R. McKinley, J Appl Phycol 6, 45 (1994)

176. D.R. Sauerbeck, Nutr Cycl Agroecosystems 60, 253 (2001)

177. A. Alissandratos, H.K. Kim, C.J. Easton, Bioengineered 4, 348 (2013)

178. A. Statnatiou, P.G. Loutzenhiser, A. Steinfeld, Chem Mater 22, $851(2010)$

179. C.W. Li, M.W. Kanan, J Am Chem Soc 134, 7231 (2012) 
180. M. Le, M. Ren, Z. Zhang, P.T. Sprunger, R.L. Kurtz, J.C. Flake, J Electrochem Soc 158, E45 (2011)

181. S. Qin, F. Xin, Y. Liu, X. Yin, W. Ma, J Colloid Interface Sci 356, $257(2011)$

182. Q.-H. Zhang, W.-D. Han, Y.-J. Hong, J.-G. Yu, Catal Today 148 , 335 (2009)

183. J. Cheng, M. Zhang, G. Wu, X. Wang, J. Zhou, K. Cen, Environ Sci Technol 48, 7076 (2014)

184. J.A. Keith, E.A. Carter, J Am Chem Soc 134, 7580 (2012)

185. P. Li, J. Xu, H. Jing, C. Wu, H. Peng, J. Lu, H. Yin, Appl Catal B 156-157, 134 (2014)

186. Z. Yang, J. Xu, C. Wu, H. Jing, P. Li, H. Yin, Appl Catal B 156157, 249 (2014)

187. P. Li, J. Zhang, H. Wang, H. Jing, J. Xu, X. Sui, H. Hu, H. Yin, Catal Sci Technol 4, 1070 (2014)

188. J.F. Brito, A.A. Silva, A.J. Cavalheiro, M.V.B. Zanoni, Int J Electrochem Sci 9, 5961 (2014)

189. G. Ghadimkhani, N.R. de Tacconi, W. Chanmanee, C. Janaky, K. Rajeshwar, Chem Commun 49, 1297 (2013)

190. M. Halmann, Nature 275, 15 (1978)

191. B. Aurian-Blajeni, I. Taniguchi, J.O. Bockris, J Electroanal Chem 149, 291 (1983)

192. J.O. Bockris, J.C. Wass, Mater Chem Phys 22, 249 (1989)

193. S. Kaneco, H. Katsumata, T. Suzuki, K. Ohta, Appl Catal B 64, 139 (2006)

194. C. Ampelli, G. Centi, R. Passalacqua, S. Perathoner, Energy Environ Sci 3, 292 (2010)

195. T. Inoue, A. Fujishima, S. Konishi, K. Honda, Nature 277, 637 (1979)

196. M. Zafrir, M. Ulman, Y. Zuckerman, M. Halmann, J Electroanal Chem Interfacial Electrochem 159, 373 (1983)

197. C.R. Cabrera, H.D. Abruña, J Electroanal Chem 209, 101 (1986)

198. L. Junfu, C. Baozhu, J Electroanal Chem 324, 191 (1992)

199. S. Ichikawa, Energy Convers Manage 36, 613 (1995)

200. G. Ramírez, G. Ferraudi, Y.-Y. Chen, E. Trollund, D. Villagra, Inorganica Chim Acta 362, 5 (2009)

201. T. Arai, S. Sato, K. Uemura, T. Morikawa, T. Kajino, T. Motohiro, Chem Commun (Camb) 46, 6944 (2010)

202. S.C. Roy, O.K. Varghese, M. Paulose, C.A. Grimes, ACS Nano 4, 1259 (2010)

203. Y. Hori, A. Murata, R. Takahashi, J. Chem. Soc. Faraday Trans. 1 Phys. Chem. Condens. Phases 85, 2309 (1989)

204. S. Ikeda, T. Takagi, K. Ito, Bull Chem Soc Jpn 60, 2517 (1987)

205. N.M. Dimitrijevic, B.K. Vijayan, O.G. Poluektov, T. Rajh, K.A. Gray, H. He, P. Zapol, J Am Chem Soc 133, 3964 (2011)

206. C. Wang, X. Ma, J. Li, L. Xu, F. Zhang, J Mol Catal A: Chem 363-364, 108 (2012)

207. R. Aydin, F. Koleli, J Electroanal Chem 535, 107 (2002)

208. M.M. Halmann, M. Steinberg, Greenhouse Gas Carbon Dioxide Mitigation: Science, Technology, 6th edn. (Lewis, Boca Raton, 1999)

209. Y. Momose, K. Sato, O. Ohno, Surf Interface Anal 34, 615 (2002)

210. R.P.S. Chaplin, A.A. Wragg, J Appl Electrochem 33, 1107 (2003)

211. M. Azuma, K. Hashimoto, M. Hiramoto, M. Watanabe, T. Sakata, J Electrochem Soc 137, 1772 (1990)

212. M. Jitaru, J Fo Univ Chem Technol Metall 42, 333 (2007)

213. B. Innocent, D. Liaigre, D. Pasquier, F. Ropital, J.-M. Léger, K.B. Kokoh, J Appl Electrochem 39, 227 (2009)

214. H. Noda, S. Ikeda, Y. Oda, K. Ito, Chem Lett 18, 289 (1989)

215. S. Kaneco, K. Iiba, H. Katsumata, T. Suzuki, K. Ohta, J Solid State Electrochem 11, 490 (2007)

216. R. Schrebler, P. Cury, C. Suarez, E. Muñoz, H. Gomez, R. Córdova, J Electroanal Chem 533, 167 (2002)

217. H.W. Nasution, E. Purnama, K. Riyani, J. Gunlazuardi, World Appl Sci J 6, 112 (2009)

218. K.W.J. Frese, J Electrochem Soc 138, 3338 (1991)
219. K. Hara, A. Kudo, T. Sakata, J Electroanal Chem 391, 141 (1995)

220. Y. Terunuma, A. Saitoh, Y. Momose, J Electroanal Chem 434, 69 (1997)

221. J. Lee, Y. Tak, Electrochim Acta 46, 3015 (2001)

222. S. Sato, T. Arai, T. Morikawa, K. Uemura, T.M. Suzuki, H. Tanaka, T. Kajino, J Am Chem Soc 133, 15240 (2011)

223. C.M. Sánchez-Sánchez, V. Montiel, D.A. Tryk, A. Aldaz, A. Fujishima, Pure Appl Chem 73, 1917 (2001)

224. J. Wu, F.G. Risalvato, F.-S. Ke, P.J. Pellechia, X.-D. Zhou, J Electrochem Soc 159, F353 (2012)

225. K. Ogura, J. CO2 Util. 1, 43 (2013)

226. K.L. Sowers, A. Fillinger, J Electrochem Soc 156, F80 (2009)

227. S. Choudhary, S. Upadhyay, P. Kumar, N. Singh, V.R. Satsangi, R. Shrivastav, S. Dass, Int J Hydrogen Energy 37, 18713 (2012)

228. J. Chen, Y. Lu, L. Guo, X. Zhang, P. Xiao, Int J Hydrogen Energy 35, 7134 (2010)

229. S.I. Maintinguer, B.S. Fernandes, I.C.S. Duarte, N.K. Saavedra, M.A.T. Adorno, M.B.A. Varesche, Int J Hydrogen Energy 36, 13508 (2011)

230. W. Jiang, J. Liu, C. Li, Inorg Chem Commun 16, 81 (2012)

231. H. Park, A. Bak, Y.Y. Ahn, J. Choi, M.R. Hoffmannn, J Hazard Mater 211-212, 47 (2012)

232. L.J. Minggu, W.R. Wan Daud, M.B. Kassim, Int J Hydrogen Energy 35, 5233 (2010)

233. M. Paulose, G.K. Mor, O.K. Varghese, K. Shankar, C.A. Grimes, J Photochem Photobiol A 178, 8 (2006)

234. Z. Liu, B. Pesic, K.S. Raja, R.R. Rangaraju, M. Misra, Int J Hydrogen Energy 34, 3250 (2009)

235. Q. Chen, J. Li, B. Zhou, M. Long, H. Chen, Y. Liu, W. Cai, W. Shangguan, Electrochem Commun 20, 153 (2012)

236. W. Zhao, Z. Wang, X. Shen, J. Li, C. Xu, Z. Gan, Int J Hydrogen Energy 37, 908 (2012)

237. X. Zhang, D. Chandra, M. Kajita, H. Takahashi, L. Dong, A Shoji, K. Saito, T. Yui, M. Yagi, Int. J. Hydrogen Energy 4 (2014)

238. W.J. Lee, P.S. Shinde, G.H. Go, E. Ramasamy, Int J Hydrogen Energy 36, 5262 (2011)

239. C.W. Lai, S. Sreekantan, Mater Sci Semicond Process 87, 294 (2013)

240. C.W. Lai, S. Sreekantan, Int J Hydrogen Energy 38, 2156 (2013)

241. M. Zhong, J. Shi, F. Xiong, W. Zhang, C. Li, Sol Energy 86, 756 (2012)

242. Y. Liu, H. Zhou, B. Zhou, J. Li, H. Chen, J. Wang, J. Bai, W. Shangguan, W. Cai, Int J Hydrogen Energy 36, 167 (2011)

243. W. Nam, S. Oh, H. Joo, S. Sarp, J. Cho, B.-W. Nam, J. Yoon, Sol Energy Mater Sol Cells 94, 1809 (2010)

244. C.-J. Tseng, C.-L. Tseng, Int J Hydrogen Energy 36, 6510 (2011)

245. S. Nissen, B.D. Alexander, I. Dawood, M. Tillotson, R.P.K. Wells, D.E. Macphee, K. Killham, Environ Pollut 157, 72 (2009)

246. Z. Frontistis, V.M. Daskalaki, A. Katsaounis, I. Poulios, D. Mantzavinos, Water Res 45, 2996 (2011)

247. E. Brillas, C.A. Martínez-Huitle, Appl Catal B 166-167, 603 (2015)

248. K. Li, H. Zhang, Y. He, T. Tang, D. Ying, Y. Wang, T. Sun, J. Jia, Chem Eng J 268, 10 (2015)

249. R. Portela, S. Suárez, R.F. Tessinari, M.D. Hernández-Alonso, M.C. Canela, B. Sánchez, Appl Catal B 105, 95 (2011)

250. I. Tantis, L. Bousiakou, Z. Frontistis, D. Mantzavinos, I. Konstantinou, M. Antonopoulou, G.-A. Karikas, P. Lianos, J Hazard Mater 294, 57 (2015)

251. I. Oller, S. Malato, J.A. Sanchez-Perez, Sci Total Environ 409, $4141(2011)$

252. X. Zhao, J. Qu, H. Liu, C. Wang, S. Xiao, R. Liu, P. Liu, H. Lan, C. Hu, Bioresour Technol 101, 865 (2010)

253. J. Dasgupta, J. Sikder, S. Chakraborty, S. Curcio, E. Drioli, J Environ Manage 147, 55 (2015) 
254. T. Oyama, T. Otsu, Y. Hidano, T. Koike, N. Serpone, H. Hidaka, Sol Energy 85, 938 (2011)

255. J.R. Bolton, K.G. Bircher, W. Tumas, C.A. Tolman, Pure Appl Chem 73, 627 (2001)

256. M. Catanho, G.R.P. Malpass, A.J. Motheo, Appl Catal B 62, 193 (2006)
257. L. Feng, E.D. van Hullebusch, M.A. Rodrigo, G. Esposito, M.A. Oturan, Chem Eng J 228, 944 (2013)

258. L.C. Almeida, B.F. Silva, M.V.B. Zanoni, J Electroanal Chem 734, 43 (2014)

259. T.E. Agustina, H.M. Ang, V.K. Vareek, J Photochem Photobiol C 6, 264 (2005)

260. M. Mehrjouei, S. Müller, D. Möller, Chem Eng J 263, 209 (2014) 